\title{
G6PD promotes renal cell carcinoma proliferation through positive feedback regulation of p-STAT3
}

\author{
Qiao Zhang ${ }^{1, *}$, Zhe Yang ${ }^{2, *}$, Qiaoqiao Han ${ }^{1, *}$, Honggang Bai ${ }^{1}$, Yanling Wang ${ }^{1}$, Xiaojia \\ $\mathrm{Yi}^{3}$, Zihan $\mathrm{Yi}^{1}$, Lijuan Yang ${ }^{1}$, Lu Jiang ${ }^{1}$, Xin Song ${ }^{4}$, Yingmin Kuang ${ }^{5}$ and Yuechun \\ Zhu ${ }^{1}$ \\ ${ }^{1}$ Department of Biochemistry and Molecular Biology, School of Basic Medical Sciences, Kunming Medical University, Chenggong \\ District, Kunming 650500, Yunnan Province, China \\ ${ }^{2}$ Department of Pathology, The First Affiliated Hospital of Kunming Medical University, Wuhua District, Kunming 650032, \\ Yunnan Province, China \\ ${ }^{3}$ Department of Pathology, The Second Affiliated Hospital of Kunming Medical University, Wuhua District, Kunming 650101, \\ Yunnan Province, China \\ ${ }^{4}$ Department of Cancer Biotherapy Center, The Third Affiliated Hospital of Kunming Medical University, Xishan District, \\ Kunming 650118, Yunnan Province, China \\ ${ }^{5}$ Department of Organ Transplantation, The First Affiliated Hospital of Kunming Medical University, Wuhua District, Kunming \\ 650032, Yunnan Province, China \\ *These authors have contributed equally to this work \\ Correspondence to: Yuechun Zhu, email: zhuyuechun20091119@163.com \\ Yingmin Kuang, email: yingmin1512@aliyun.com \\ Keywords: G6PD; renal cell carcinoma; proliferation; p-STAT3; positive feedback regulation \\ Received: August 09, $2017 \quad$ Accepted: September 22, $2017 \quad$ Published: November 20, 2017 \\ Copyright: Zhang et al. This is an open-access article distributed under the terms of the Creative Commons Attribution License 3.0 \\ (CC BY 3.0), which permits unrestricted use, distribution, and reproduction in any medium, provided the original author and source \\ are credited.
}

\section{ABSTRACT}

Ectopic Glucose 6-phosphate dehydrogenase (G6PD) expression plays important role in tumor cell metabolic reprogramming and results in poor prognosis of multiple malignancies. Our previous study indicated that G6PD is overexpressed in clear cell renal cell carcinoma (CCRCC), the most common subtype of RCC. However, its role in RCC is still unclear. Here, we demonstrate that G6PD is not only up-regulated in all types of RCC specimens but also displays higher activities in RCC cell lines. G6PD overexpression promoted RCC cell proliferation, altered cell cycle distribution, and enhanced xenografted RCC development. G6PD up-regulated ROS generation by facilitating NADPH-dependent NOX4 activation, which led to increased expression of p-STAT3 and CyclinD1. Enhanced ROS generation rescued the p-STAT3 and CyclinD1 expression reduction in G6PD-knockdown cells, while ROS scavengers reversed the up-regulated p-STAT3 and CyclinD1 expression in G6PD-overexpressing cells. Furthermore, p-STAT3 activated G6PD gene expression via binding to the G6PD promoter, demonstrating that p-STAT3 forms a positive feedback regulatory loop for G6PD overexpression. G6PD expression was up or down-regulated in response to the impact of p-STAT3 activators or inhibitors. Therefore, G6PD may be an effective RCC therapeutic target.

\section{INTRODUCTION}

Glucose 6-phosphate dehydrogenase (G6PD), the first and rate-limiting enzyme of the pentose phosphate pathway (PPP), plays critical roles for nucleotide precursors generation and redox homeostasis maintenance [1]. Lately, increasing evidences show that high expression of G6PD predicts poor overall survival of patients with numbers of cancers, indicating that G6PD may play important roles in tumorigenesis [1, 2]. In addition to the 
so-called Warburg effect, G6PD was aberrantly activated in order to generate sufficient building blocks required for rapid proliferation and adaptation of cancer cells to the altered internal and external environment $[1,3]$. Our recent studies demonstrate that G6PD is significantly higher expressed in advanced status of clear cell renal cell carcinoma (ccRCC) and closely correlates to the tumor extent, lymph node metastasis, Fuhrman grade, TNM stage and poor overall survival of ccRCC [4]. ccRCC is the most common subtypes of RCC and constitutes approximately $80 \sim 90 \%$ of RCCs. However, the expression pattern of G6PD in all the RCC cases is poorly reported, and the roles and underlying mechanisms of G6PD in RCC development, to date, remain largely unknown [4].

RCC is the most prevalent and dangerous malignancy of the kidney with a median survival time of about 13 months and less than $10 \%$ of patients with RCC will survive more than 5 years [5-7]. Each year, approximately 210,000 new cases of RCC are diagnosed $[5,6]$. Although many advances have been made in RCC diagnosis and treatment, the molecular mechanisms that govern RCC initiation and progression are poorly understood. Therefore, identifying novel genes that are functionally involved in tumorigenesis is critical and may provide more sophisticated early diagnostic and therapeutic strategies for RCC.

Many studies have suggested that RCC is fundamentally a metabolic disease [8] and that an altered metabolism is involved in RCC tumorigenesis [9, 10]. Moreover, numerous genes involved in RCC development play an essential part in mediating carcinoma cell metabolism $[11,12]$. Based on these facts, we tentatively hypothesize that there must be a close underlying correlation between G6PD and RCC tumorigenesis. It has been reported that, G6PD plays important roles in the regulation of reactive oxygen species (ROS) generation [1]. As the PPP is activated, G6PD is usually considered the pacesetter for nicotinamide adenine dinucleotide phosphate (NADPH) production in cancer cells $[1,2$, 13]. NADPH is a substrate of NADPH oxidases and functionally important hydrogen donor that serves as a cofactor in anabolic reactions of fatty acids, isoprenoids, and aromatic amino acids synthesis [14]. ROS are primarily produced by NADPH oxidases (NOX) of the NOX family which includes five homologs, NOX1 to NOX5, and two related enzymes DUOX1 and DUOX2 [15-17]. It has been confirmed that NOX oxidases, particularly the isoform NOX4, are the major source of ROS in RCC [18-20].

NOX4, especially the membrane-bound NOX4, plays a major role in regulating cellular functions and is thought to be an electron transporter [13, 15, 21]. In combination with NADPH, NOX4 could pass the electrons to an electron acceptor according to the equation $\mathrm{NADPH} \rightarrow \mathrm{FAD} \rightarrow \mathrm{Heme} \rightarrow \mathrm{O}_{2}$ to generate $\mathrm{O}_{2}{ }^{-}$. Then, $\mathrm{O}_{2}^{-}$will be catalyzed sequentially into the downstream products containing $\mathrm{H}_{2} \mathrm{O}_{2}$ and $\mathrm{OH} . \mathrm{O}_{2}^{-}, \mathrm{H}_{2} \mathrm{O}_{2}$ and $\mathrm{OH}$ are members of the ROS family [15]. Accordingly, both G6PD and NOX4 are important in cellular ROS metabolism and may synergistically act in regulation of redox homeostasis in RCC [13]. However, limited information is available about the regulatory relationship between G6PD and ROS levels in RCC. Before the experiment carried out, we could not assume that G6PD overexpression will increase or decrease ROS generation. Because it has been clarified that G6PD could probably promote ROS production through the process we described, but may also have the abilities to eliminate ROS via the reduced form of glutathione. Reduced glutathione (GSH) depends on NADPH to maintain its reducing state and acts as a scavenger for dangerous oxidative metabolites [22].

In this study, we firstly analyzed the expression profile of G6PD using bioinformatics and immunohistochemical techniques. To better understand the function of G6PD in RCC, stable G6PD-overexpressing and knockdown RCC cells were established, and the effects of G6PD on RCC proliferation were assessed both in vitro and in vivo. Furthermore, the potential molecular mechanisms underlying G6PD-promoted tumorigenesis and the reason for aberrant G6PD expression in RCC were investigated.

\section{RESULTS}

\section{G6PD is overexpressed in human renal cell carcinoma samples}

A gene expression profile reveals essential clues about the function of a gene. We previously reported the aberrant expression of G6PD in ccRCC [4]. In the present study, we further explore the association between G6PD and RCC through data mining of the public Gene Expression Omnibus (GEO) of $72 \mathrm{ccRCC}$ and the adjacent non-tumor tissues (GSE53757). The results showed that G6PD mRNA levels were significantly higher in ccRCC tissues than in the adjacent tissues ( $p<0.01$, Figure 1A). This conclusion is not totally the same as our previous statistical analyses of The Cancer Genome Atlas (TCGA) datasets [4], but provides sufficient information for further unravelling the correlation between G6PD overexpression and RCC tumor initiation and progression.

$\mathrm{RCC}$ is a type of malignant tumor originating from the epithelial cells of the renal tubule or collecting duct in the kidney. The most predominant subtype of RCC is ccRCC and the other histologic subtypes of RCC, papillary (pRCC) and chromophobe (chRCC) constitute 15\% and $5 \%$ of RCC cases, respectively [23]. To examine the pathological relevance of G6PD in all RCCs development, the protein levels and cellular distribution of G6PD in RCC (60 ccRCC, 10 pRCC and 4 chRCC samples which were in parallel with the proportion of each RCC subtype) were analyzed using immunohistochemistry. 
Though there were no obvious expression differences between the different subtypes, the results have showed that the expression of G6PD was significantly increased in the total of 74 RCC specimens $(p<0.001$, Table 1$)$.
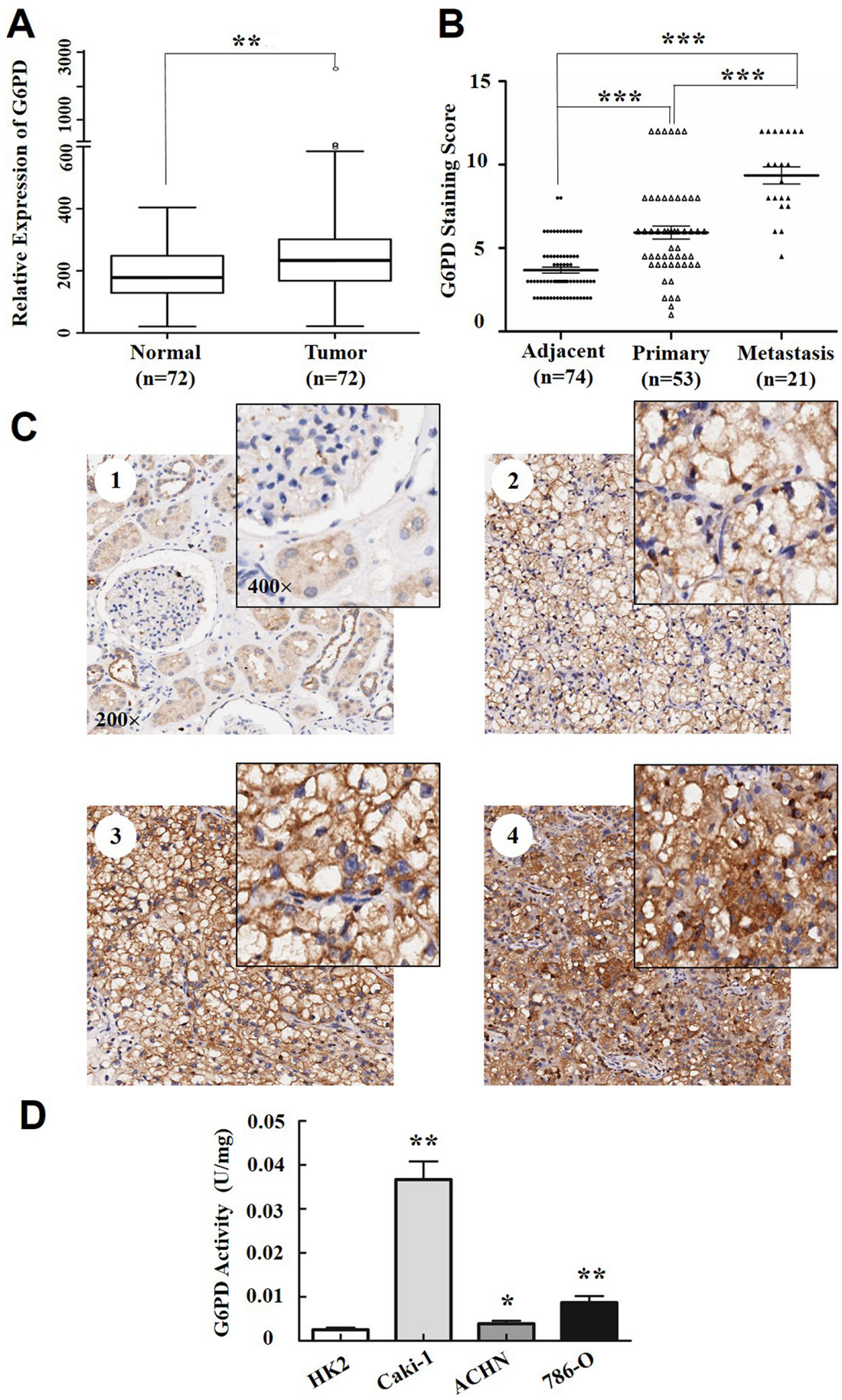

Figure 1: G6PD is overexpressed in RCC. (A) Expression profiling of G6PD from Gene Expression Omnibus (GEO) datasets in ccRCC samples and normal renal tissues $(\mathrm{n}=72) .{ }^{* *} p<0.01$ vs. Normal (Wilcoxon rank-sum test). (B) Staining scores of G6PD in adjacent normal tissues $(\mathrm{n}=74)$, primary RCC without lymph node or distant metastasis $(\mathrm{n}=53)$ and metastasis $\mathrm{RCC}(\mathrm{n}=21) .{ }^{* * *} p<0.001$ vs. Adjacent or Primary (Kruskal-Wallis one-way analysis). (C) Representative images of immunohistochemical staining and cellular distributions for G6PD in noncancerous renal tissues (C1, weak G6PD expression), early TNM stage (C2, moderate G6PD expression), Stage III and Stage IV (C3-C4, strong G6PD expression) RCC samples. Images were captured using $20 \times$ and $40 \times$ objective lens. (D) G6PD activity assays in HK2 (human renal tubular epithelial cell line) and 3 RCC cell lines (Caki-1, ACHN and 786-O). ${ }^{*} p<0.05,{ }^{* *} p<0.01$ vs. HK2 (one-way ANOVA). Values are means \pm SD of three independent experiments, each performed in triplicate. 
Table 1: Expression of G6PD in human renal cell carcinoma (RCC)

\begin{tabular}{lcccc}
\hline Samples & No. & & Expression of G6PD & \multirow{2}{*}{$\boldsymbol{p}$ value } \\
\cline { 3 - 5 } & & Low (\%) & High (\%) & Avg. score \\
\hline Adjacent & 74 & $60(81.08)$ & $14(18.92)$ & 3.682 \\
RCC & 74 & $24(32.43)$ & $50(67.57)$ & 6.905 \\
\hline
\end{tabular}

$\chi^{2}$ test

High expression level of G6PD was detected in $18.92 \%$ $(14 / 74)$ of the non-cancerous renal tissues but in $67.57 \%$ (50/74) of the RCC tissues. Moreover, G6PD expression was significantly higher in the RCC metastasis than that detected in normal adjacent tissues or primary RCC without lymph node or distant metastasis (Figure 1B). As shown in Figure 1C1, the predominant G6PD localization within the normal parenchyma was in renal tubular cells, but at lower expression levels in other cell types, including glomerular mesangial cells. Additionally, G6PD was mainly localized in the cytoplasm of the renal tumor cells, with different staining intensities in different TNM stages of RCC (Figure 1C2-C4).

Likewise, the enzyme activities of G6PD were also significantly higher in RCC cell lines (ACHN, 786-O, Caki-1) than in the renal tubular epithelial cell line HK2 (Figure 1D), according to the results from analyses using the G6PD assay kit. These results indicate that G6PD is highly expressed and overactive in RCC and might be tightly correlated to renal tumorigenesis.

\section{G6PD promotes RCC cell proliferation in vitro and enhances tumor growth in vivo}

To explore the function of G6PD overexpression in RCC, we firstly transfected ACHN and 786-O cells with pBABE-puro-G6PD, or pSR-GFP/Neo-G6PD shRNA plasmid to establish stable G6PD-overexpressing or knockdown RCC cell lines. Real-time RT-PCR and Western blot were used to quantify the expression levels of G6PD. The results showed that these stable cell lines were established successfully (Supplementary Figure 1).

Based on the importance of G6PD in nucleotide precursors production, we wonder whether G6PD overexpression plays a role in promoting $\mathrm{RCC}$ cell growth. As expected, the Cell Counting Kit-8 (CCK-8) detection results showed that when G6PD protein level was up or down-regulated, notable promotion or reduction of cell proliferation were observed in ACHN (Figure 2A) and 786-O stable cell lines (Figure 2B). Consistently, the colony formation assay also revealed that G6PD overexpression in ACHN cells showed significantly increased colony formation index compared with the control cells (Figure 2C, 2D), while reduced colony formation index were observed in G6PD-knockdown 786$\mathrm{O}$ cells (Figure 2E, 2F).
To further elucidate the role of G6PD underlying RCC cell growth, the cell cycle distribution of RCC cells was analyzed by flow cytometry. The results revealed that G6PD-overexpressing ACHN and 786-O cells had a decreased cell population in the $\mathrm{G}_{0} / \mathrm{G}_{1}$ phase and a significant increase in the $\mathrm{S}$ and $\mathrm{G}_{2} / \mathrm{M}$ phase compared with the control cells (Figure 2G, 2H). Meanwhile, G6PD knockdown increased the proportion of 786-O cells in the $\mathrm{G}_{0} / \mathrm{G}_{1}$ phase and decreased the proportion of cells in the $\mathrm{S}$ and $\mathrm{G}_{2} / \mathrm{M}$ phases (Figure $2 \mathrm{H}$ ). These results indicate that G6PD facilitates the cell cycle and promotes RCC cell proliferation.

The above in vitro results demonstrate that G6PD may play an oncogenic role in RCC. Therefore, we subsequently used xenograft models in nude mice to investigate whether G6PD promotes RCC tumor growth in vivo. G6PD-overexpressing, G6PD-knockdown or respective control 786-O cells were injected subcutaneously into the right oxter flanks of nude mice. Tumor volume was measured on the indicated days after injection. We found that the growth of tumor and tumor size were significantly faster and larger with G6PDoverexpressing cells compared with the control cells (Figure 3A-3C). Conversely, the G6PD-knockdown cells produced slower and smaller tumors than those with the Non-silencer cells (Figure 3D-3F). These results confirm that G6PD potentiates RCC tumorigenesis in vivo.

Taken together, in vitro and in vivo results indicate that G6PD overexpression increases RCC cell proliferation and enhances RCC tumorigenesis, whereas G6PD silencing reduces RCC cells growth and inhibits xenograft development.

\section{G6PD stimulates ROS production via the up- regulation of NOX4 activity}

As the key enzyme of the pentose phosphate pathway, G6PD plays an important role in the maintenance of the cellular redox balance by cooperating with NADPH oxidase 4 (NOX4) and synergistically regulating the production of reactive oxygen species (ROS), which is often closely correlated with tumor initiation and development $[1,24]$. To explore the mechanism of G6PD-regulated RCC cell proliferation, the activities of G6PD and NOX4, and the NADPH and ROS levels of RCC cells, were measured. As shown in Figure 4A, 4B, 
786-O cells revealed a significantly high basal activity of G6PD $(7 \pm 0.4 \mathrm{U} / \mathrm{g})$ in comparison with the ACHN cells
( $4 \pm 0.4 \mathrm{U} / \mathrm{g}$ ). Moreover, with G6PD expression levels up or down-regulated, notable promotion or inhibition of
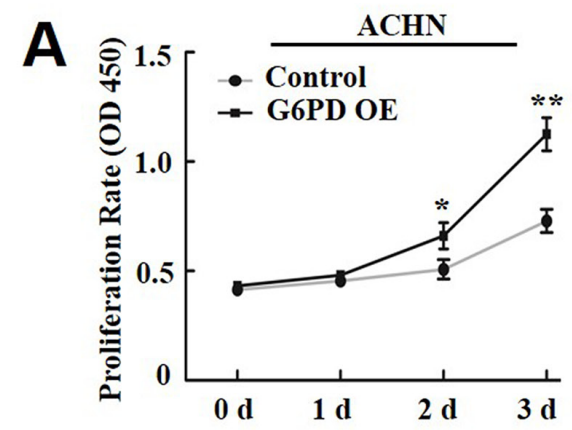

C

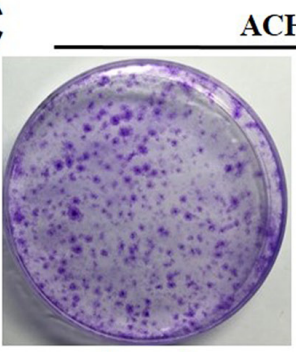

CHN

Control

E

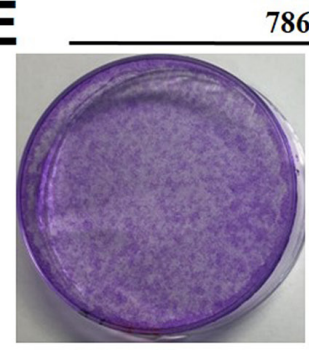

Non-silencer

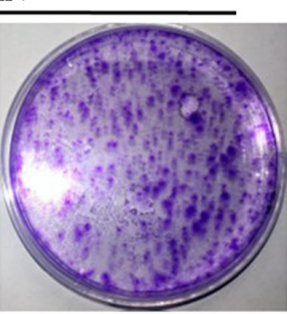

G6PD OE

786-O

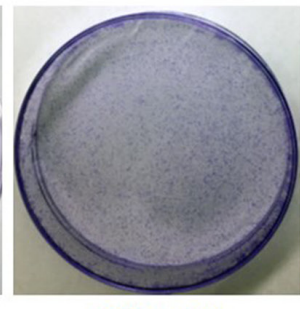

G6PD KD
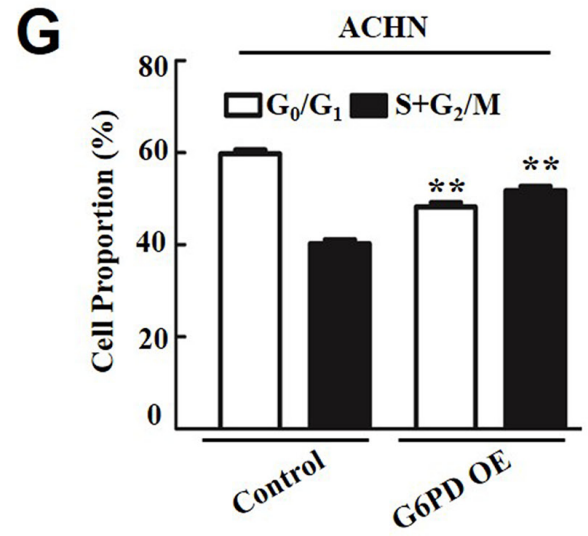

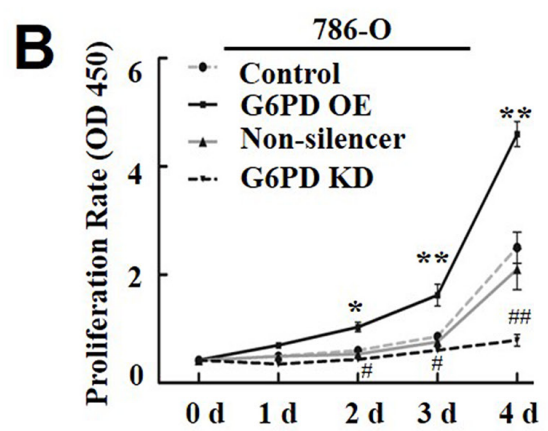

D

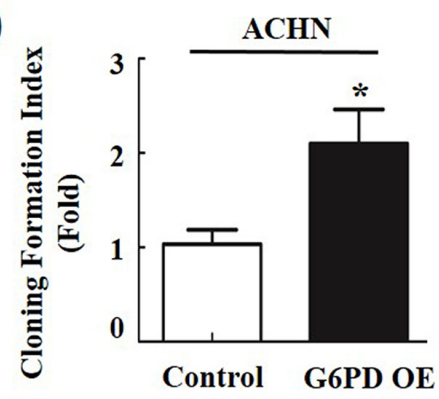

F

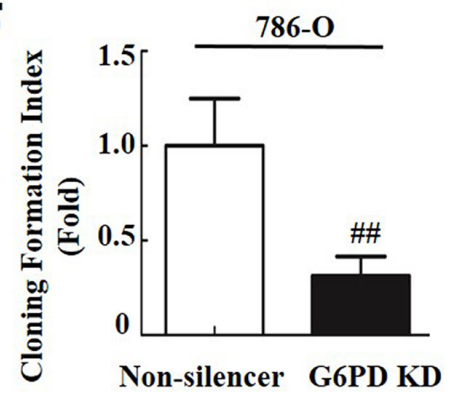

H

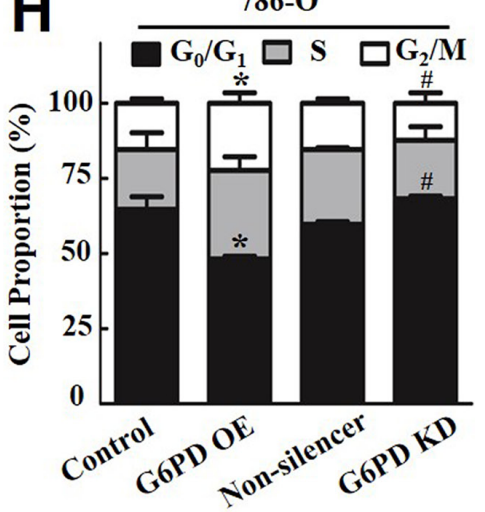

Figure 2: G6PD enhances RCC cell proliferation and affects cell-cycle phase distribution. (A-B) The cell proliferation rate of transfected ACHN (A) and 786-O cells (B) was determined using the CCK-8 assay at indicated days post-seeding. The data represent three independent experiments, each performed in triplicate. (C-F) The plate clone formation assay and quantification assessment were performed to determine the proliferation rate of ACHN (C-D) and 786-O (E-F) cells transfected with the G6PD OE plasmid, G6PD KD plasmid, or the control vectors. (G-H) Flow cytometry analysis of ACHN $(\mathrm{G})$ and 786-O $(\mathrm{H})$ cell cycle distributions. The data are means $\pm \mathrm{SD}$ from three independent experiments, each performed in triplicate. ${ }^{*} p<0.05,{ }^{* *} p<0.01 \mathrm{vs}$. Control; ${ }^{*} p<0.05$, ${ }^{\#} p<0.01 \mathrm{vs}$. Nonsilencer (unpaired Student $t$-test). Control, G6PD OE, Non-silencer and G6PD KD represent cells transfected with pBABE-puro, pBABEpuro-G6PD, pSR-GFP/Neo-Non-silencer and pSR-GFP/Neo-G6PD shRNA plasmids, respectively. 
G6PD activities were observed in corresponding ACHN (Figure 4A) or 786-O (Figure 4B) cells. Additional results indicated that overexpression of G6PD increased the levels of NADPH (Figure 4C), NOX4 enzyme activities (Figure $4 \mathrm{E}$ ) and ROS production (Figure $4 \mathrm{G}, 4 \mathrm{H}$ ) in ACHN cells, whereas, a significant decrease in NADPH levels (Figure 4D), NOX4 activity (Figure 4F) and ROS accumulation (Figure 4I, 4J) were associated with the knockdown of G6PD in comparison to the Non-silencer cells. These results show that G6PD could alter the redox status and promote ROS production partly by increasing NADPH levels and NOX4 activity in RCC cells.

\section{p-STAT3 is increased in response to G6PD- facilitated ROS accumulation}

It has been reported that signal transducer and activator of transcription 3 (STAT3) plays a vital role
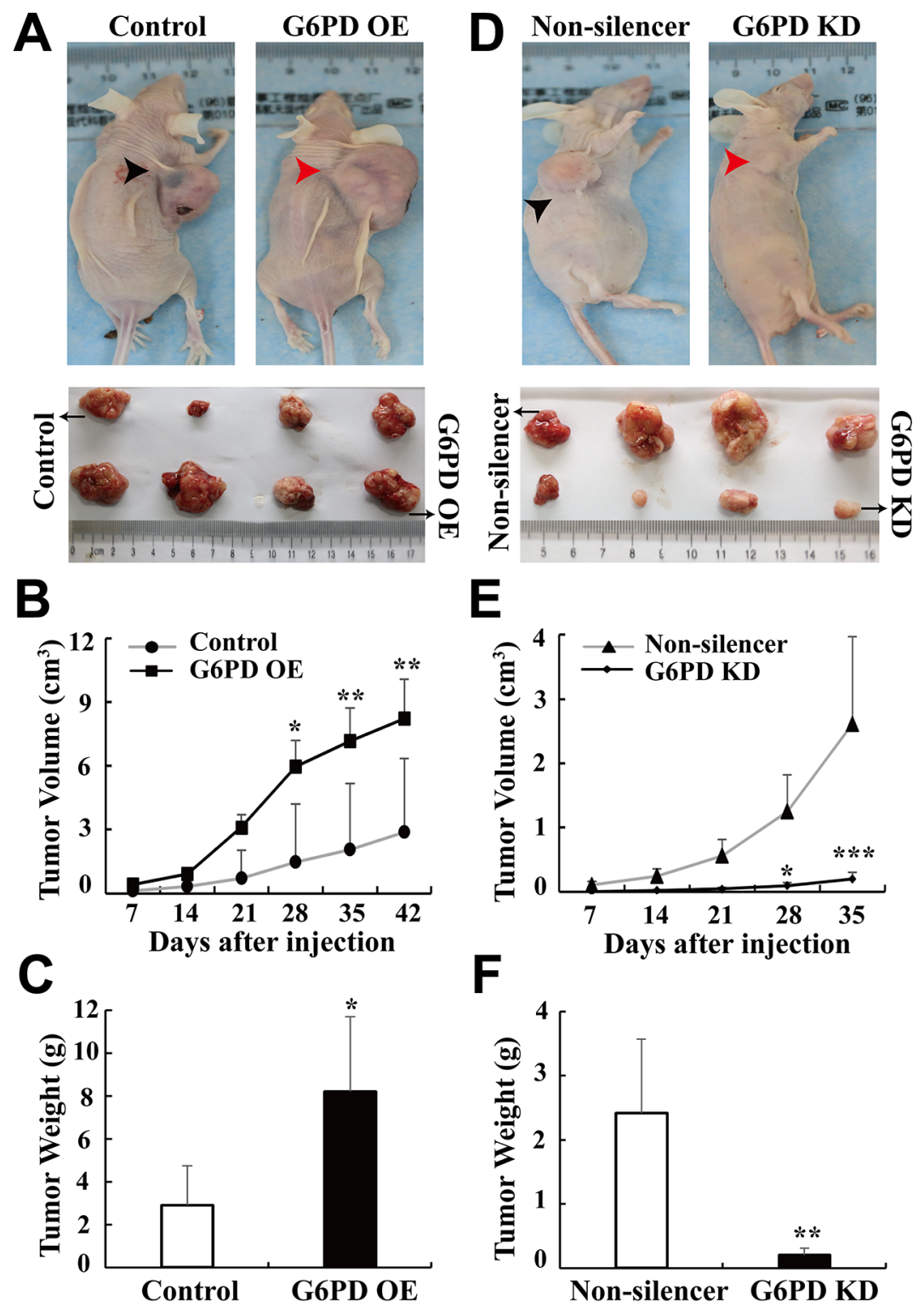

$\mathbf{E}$
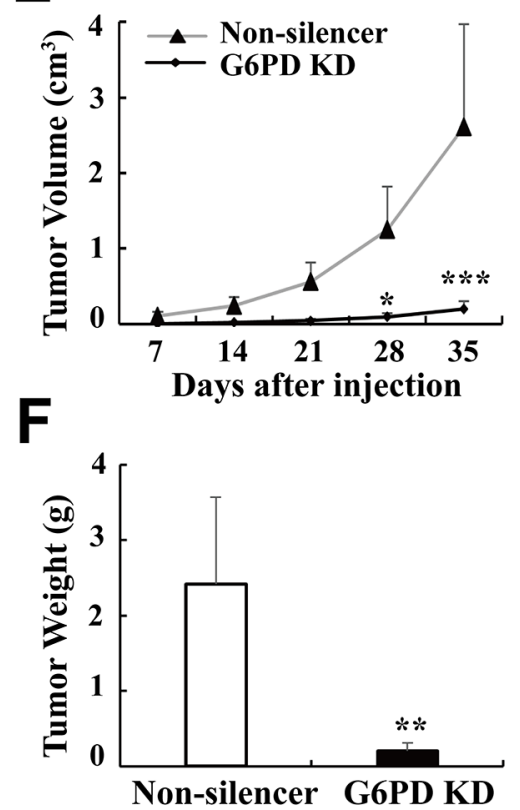

Figure 3: G6PD promotes xenografted RCC development in vivo. (A-C) 786-O cells stably transfected with $\mathrm{pBABE}-\mathrm{puro}$ (Control) or pBABE-puro-G6PD (G6PD OE), (D-E) 786-O cells stably transfected with pSR-GFP/Neo-Non-silencer (Non-silencer) or pSR-GFP/Neo-G6PD shRNA (G6PD KD). $1 \times 10^{7}$ appropriate cells were resuspended in $200 \mu \mathrm{PBS}$ and injected subcutaneously into the right oxter flank of each $\mathrm{BALB} / \mathrm{c}$ nude mice. Representative images of tumor-bearing mice (top panel) and the tumors isolated from each group (bottom panel) at day 42 (Control or G6PD OE) or day 35 (Non-silencer or G6PD KD) are shown in A and D. Tumor size was monitored at indicated days post-injection and the results are shown in $\mathrm{B}$ and $\mathrm{E} .{ }^{*} p<0.05,{ }^{* *} p<0.01,{ }^{* * *} p<0.001$ vs. Control or Nonsilencer (two-way ANOVA). Tumor weights in each group were measured after the mice were sacrificed and samples harvested (C, F). ${ }^{*} p$ $<0.05,{ }^{* *} p<0.01$ vs. Control or Non-silencer (unpaired Student $t$-test). 
in signal transduction pathways that mediate cell proliferation, partly by regulating CyclinD1 expression in RCC [25]. Furthermore, p-STAT3 (Ser727) has also been proved to be an independent prognostic factor for clear cell RCC [26]. These evidences lead us to suspect that p-STAT3 excessive activation may contribute to G6PD-stimulated RCC cell proliferation via up-regulated CyclinD1 expression. To test this hypothesis, Western blot analysis was firstly performed to identify the expression changes of p-STAT3 in RCC cells with G6PD overexpression or knockdown. The results showed that G6PD knockdown could notably attenuate the levels of p-STAT3, STAT3 and the ratio of p-STAT3/STAT3 in 786-O cells, whereas, with the G6PD overexpression, the protein level of both p-STAT3 and STAT3 were obviously increased in ACHN cells (Figure 5A, 5B). Meanwhile, the mRNA and protein levels of CyclinD1 were also down or up-regulated when G6PD was knockdown or overexpressed in RCC cells (Figure 5A, Supplementary Figure 2). These results indicate that G6PD may have the potential to increase p-STAT3 signaling activities and promote CyclinD1 transcription.

Our previous reports indicated that the aberrant ROS level could influence melanoma cell proliferation by regulating the DNA-binding activity of p-STAT3 [24]. In the present study, we next assessed whether the up-regulated expression levels of p-STAT3 were influenced by the effects of G6PD-facilitated ROS accumulation. The results showed that when 786-O cells were cultured with the ROS scavengers $\mathrm{N}$-acetyl-cysteine (NAC) or $\mathrm{H}_{2} \mathrm{O}_{2}$ (used to evaluate the ROS generation), significant promotion or inhibition of ROS levels were observed in corresponding cells in comparison with the control (Supplementary Figure 3). Consistently, ROS accumulation further promoted the expression of p-STAT3, STAT3 and the ratio of p-STAT3/STAT3 in 786-O cells (Figure 5C, Supplementary Figure 4A). Significantly reduced or elevated CyclinD1 expression at both mRNA and protein levels was also observed when 786-O cell was treated with NAC or $\mathrm{H}_{2} \mathrm{O}_{2}$ (Figure $5 \mathrm{C}$, Supplementary Figure 4B-4C). The above results imply that G6PD mediates p-STAT3 signaling activities, CyclinD1 overexpression and promoted RCC proliferation may be dependent on the up-regulation of cellular ROS accumulation.

To clarify this notion, we tested whether the ROS levels could influence the effects of G6PD dysregulation on p-STAT3 activation and CyclinD1 gene expression. The results of Supplementary Figure 5 showed that $\mathrm{H}_{2} \mathrm{O}_{2}$ addition could rescue the ROS down-regulation by G6PD knockdown in 786-O cells, whereas, NAC in ACHN cells could reverse the ROS up-regulation by G6PD overexpression. Moreover, the p-STAT3 and CyclinD1 expression reduction, mediated by G6PD knockdown, could be rescued by $\mathrm{H}_{2} \mathrm{O}_{2}$ addition in G6PDknockdown 786-O cells (Figure 5D, 5E), while the up- regulated p-STAT3 signaling activities and CyclinD1 expression could be reversed by NAC stimulation in G6PD-overexpressing ACHN cells (Figure 5F, 5G). These results proved that G6PD might promote p-STAT3 activation by mediating ROS accumulation. We then analyzed the expression of G6PD and p-STAT3 in human RCC and paired adjacent non-cancer renal tissues $(n=10)$ by immunohistochemistry. As shown in Figure 5H, 5I, the staining of both G6PD and p-STAT3 was stronger in RCC than in the adjacent tissues. Moreover, the Pearson correlation analysis revealed that the expression levels of G6PD protein are strongly correlated with p-STAT3 in human RCC samples $(\mathrm{r}=0.521, p<0.01)$. These results reveal that up-regulated co-expression of G6PD and p-STAT3 may synergistically contribute to the tumorigenesis of RCC.

Taken together, G6PD promotes tumor cell proliferation possibly through ROS-stimulated persistent activation of p-STAT3 signaling and up-regulated CyclinD1 expression in RCC.

\section{p-STAT3 binds directly to the G6PD promoter}

p-STAT3 is a transcriptional factor that preferentially binds to the TTN5AA consensus regulatory sequences of its target genes and activates their expression [27, 28]. Interestingly, after the 786-O cells were treated with NAC or $\mathrm{H}_{2} \mathrm{O}_{2}$ as above, we could observe a significant decrease or increase of G6PD expression at both mRNA and protein levels (Supplementary Figure 4D-4E and Figure 5C), which was consistent with the p-STAT3 signaling activity changes. Therefore, we hypothesize that p-STAT3 may be a novel transcriptional regulator of G6PD gene expression, and thus form a positive feedback loop to contribute to G6PD up-regulation in RCC.

To investigate whether p-STAT3 activates G6PD transcription, bioinformatics analysis was performed using MatInspector software. The results showed that the transcriptional regulatory region of G6PD had conserved p-STAT3 binding TTN5AA sequences (Figure 6A). We then constructed G6PD-luc which contained the p-STAT3 binding site on the G6PD promoter for the luciferase reporters assay. Following the transfection of G6PDluc and vectors encoding either the mutant STAT3 $\mathrm{C}$ or STAT3 DN, which actively up or down-regulates STAT3 signaling pathway persistently $[28,29]$, the stimulated increase or reduction of G6PD-luc activity occurred in a dose-dependent manner in 786-O cells (Figure 6B). The G6PD-luc mutant, or deletion containing the mutant or deleted p-STAT3 binding site (Figure 6A), exhibited significantly decreased p-STAT3 activity as compared to the wild type (Figure 6C), indicating that p-STAT3 plays an important role in activating G6PD mRNA expression.

To further assess whether p-STAT3 facilitates G6PD transcription by directly targeting the G6PD locus, a specific primer covering the potential p-STAT3 

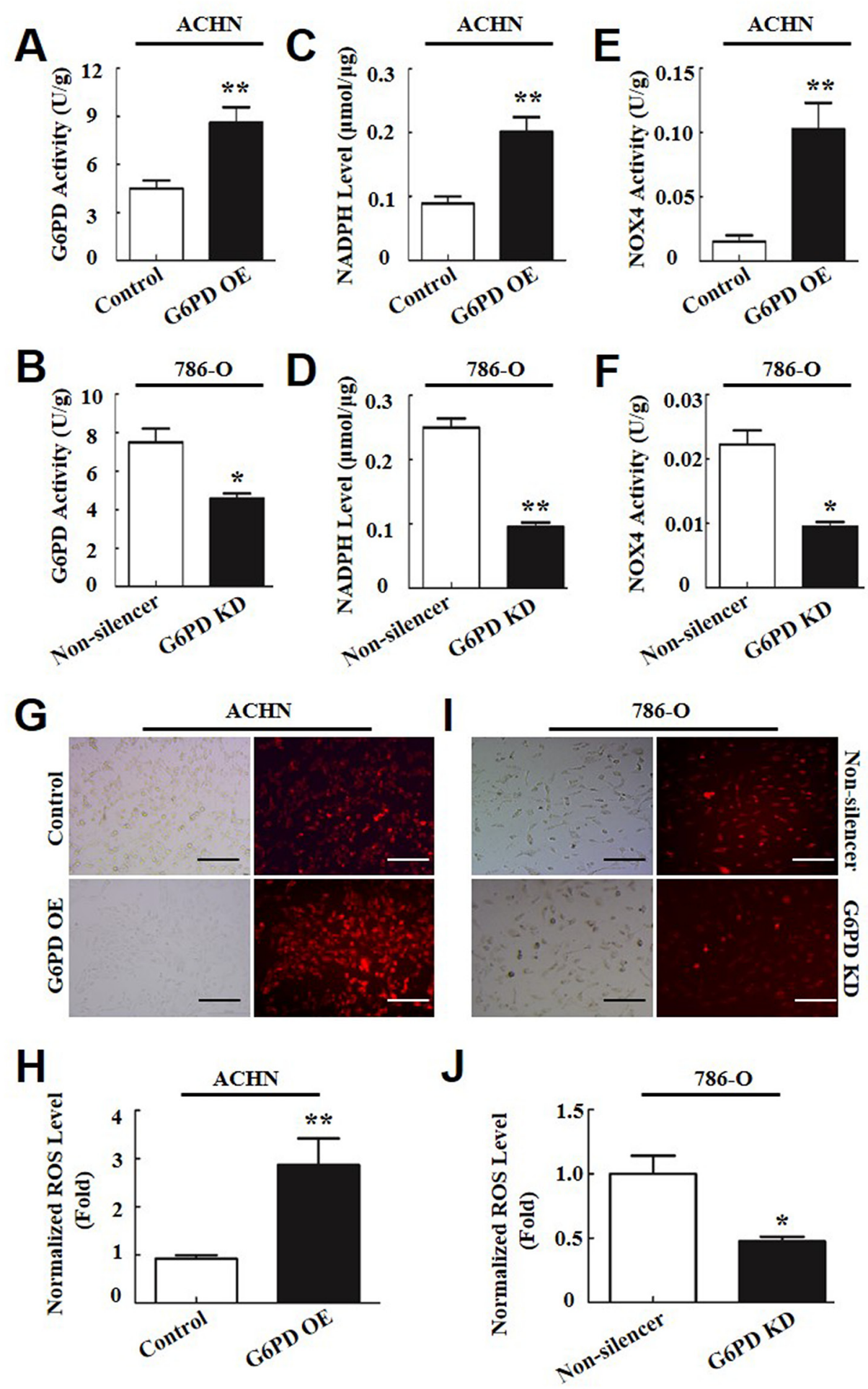

Figure 4: G6PD promotes ROS production by increasing NOX4 activity in RCC cells. (A-F) G6PD activities (A-B), NADPH levels (C-D) and NOX4 activities (E-F) were analyzed using the respective assay kit in ACHN (A, C, E) and 786-O cells (B, D, F). (G-J) ROS accumulation was measured using fluorescence microscopy (G, I) and flow cytometry analysis (H, J) in ACHN (G, H) and 786-O (I, J) cells. The left images of $\mathrm{G}$ and I were taken under normal light and the right images were taken under fluorescence. Scale bar $=200 \mu \mathrm{m}$. The data are means $\pm \mathrm{SD}$ from three independent experiments, each performed in triplicate. ${ }^{*} p<0.05,{ }^{* *} p<0.01,{ }^{* * *} p<0.001$ vs. Control or Non-silencer (unpaired Student $t$-test). 
binding site located between -1729 and -1493 bp of the G6PD promoter was designed (Figure 6A). Using DNA fragments precipitated with anti-p-STAT3 antibody, the chromatin immunoprecipitation (ChIP) assay showed that p-STAT3 was recruited to the G6PD promoter about 2 folds as compared with IgG (Figure 6D, 6E), suggesting that p-STAT3 could bind on the G6PD transcriptional regulatory region. These data indicate that the functional p-STAT3 may act as a direct regulator of G6PD gene transcription in RCC cells.

\section{p-STAT3 contributes to G6PD overexpression in RCC cells}

To explore whether p-STAT3 is involved in G6PD up-regulation in RCC, Real-time RT-PCR and Western blot were used to analyze the impact of p-STAT3 activators (interleukin 6, IL6) or inhibitors (STATTIC) on G6PD expression. The results showed that IL6, which promoted p-STAT3 activity, increased the levels of G6PD transcription in ACHN and 786-O stable cells by about 1.5 2 folds relative to the BSA controls (Figure 7A, 7B). Whereas, the expression of G6PD at the mRNA level was notably reduced by the p-STAT3 signaling inhibitor STATTIC in both ACHN and 786-O cells (Figure 7C, 7D). Additional Western blot and grayscale scanning analyses showed that the significantly increased G6PD expression at the protein level was positively associated with the activation of p-STAT3 after treatment with IL6 (Figure 7E, 7F). Conversely, after stimulated with STATTIC, the expression of G6PD obviously decreased in RCC cells (Figure $7 \mathrm{G}, 7 \mathrm{H}$ ). Taken together, these results show that
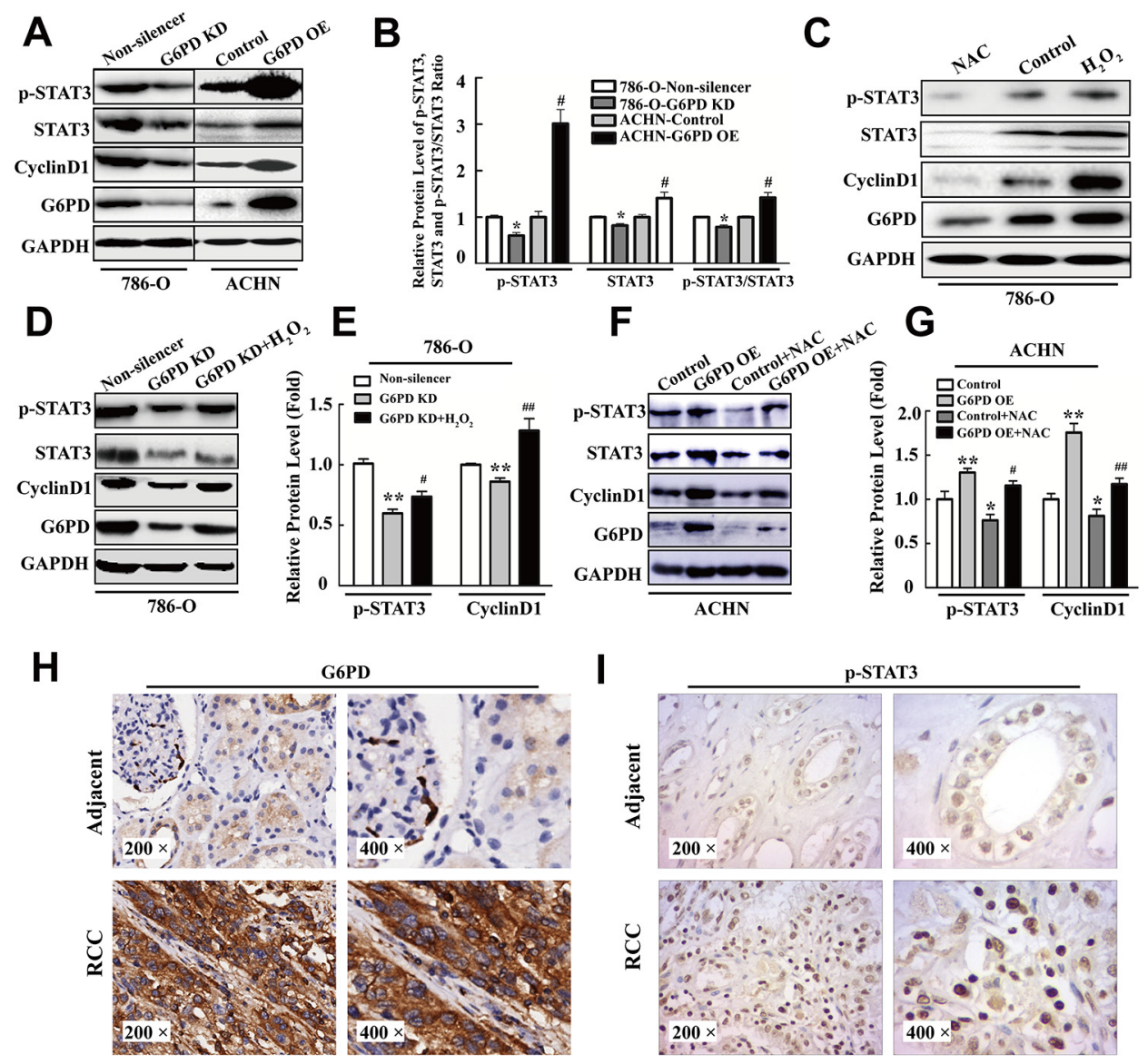

Figure 5: p-STAT3 is increased by G6PD-facilitated ROS accumulation in RCC. (A-B) Western blot assay for p-STAT3, STAT3, CyclinD1 and G6PD expression level (A) and grayscale scanning analysis (B) in 786-O and ACHN cells with stable G6PD knockdown or overexpression. (C) 786-O cells were analyzed by Western blot for p-STAT3, STAT3, CyclinD1 and G6PD expression after treatment with $20 \mathrm{mM} \mathrm{NAC}$ for $24 \mathrm{~h}$ or $1 \mathrm{mM} \mathrm{H}_{2} \mathrm{O}_{2}$ for $2 \mathrm{~h}$. Bars represent the means $\pm \mathrm{SD}$ from three independent experiments, each performed in triplicate. ${ }^{*} p<0.05$ vs. 786-O-Non-silencer; ${ }^{\#} p<0.05$ vs. ACHN-Control (unpaired Student $t$-test). (D-G) p-STAT3, CyclinD1 and G6PD expression levels were measured by Western blot (D, F) and grayscale scanning (E, G) after treatment with $1 \mathrm{mM}$ $\mathrm{H}_{2} \mathrm{O}_{2}$ in 786-O cells for $2 \mathrm{~h}$ or $20 \mathrm{mM} \mathrm{NAC}$ in ACHN cells for $24 \mathrm{~h}$. Bars represent the means $\pm \mathrm{SD}$ from three independent experiments, each performed in triplicate. ${ }^{*} p<0.05,{ }^{* *} p<0.01$ vs. Non-silencer or Control; ${ }^{\#} p<0.05,{ }^{\#} p<0.01$ vs. G6PD-KD or G6PD-OE (one-way ANOVA). (H-I) Immunohistochemistry analysis for G6PD (H) and p-STAT3 (I) were performed in adjacent noncancerous renal tissues (upper row) and RCC tissues (lower row). Representative images are shown (200× and 400×). 


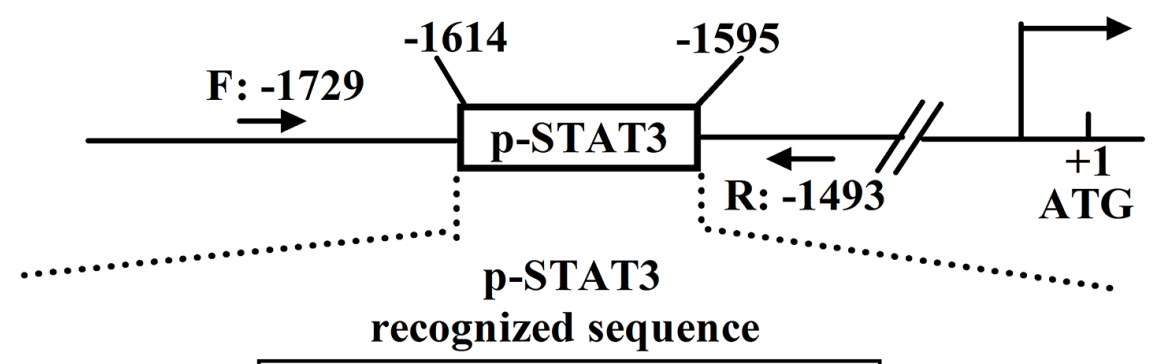

Rat 5' AGCCCTGTTTTTGGgGAAGAGGACCACAC 3'

Mouse 5' AGCCQTGTCTTTGGAGAAGAGGACCACAC 3'

Human 5' AACCQTGTCTTtgGgGaAaAgGaCCACAC 3' Wild Type

Human $5^{\prime}$...............TGCTeccGGGaggAAGGAC..................... 3' Mutant
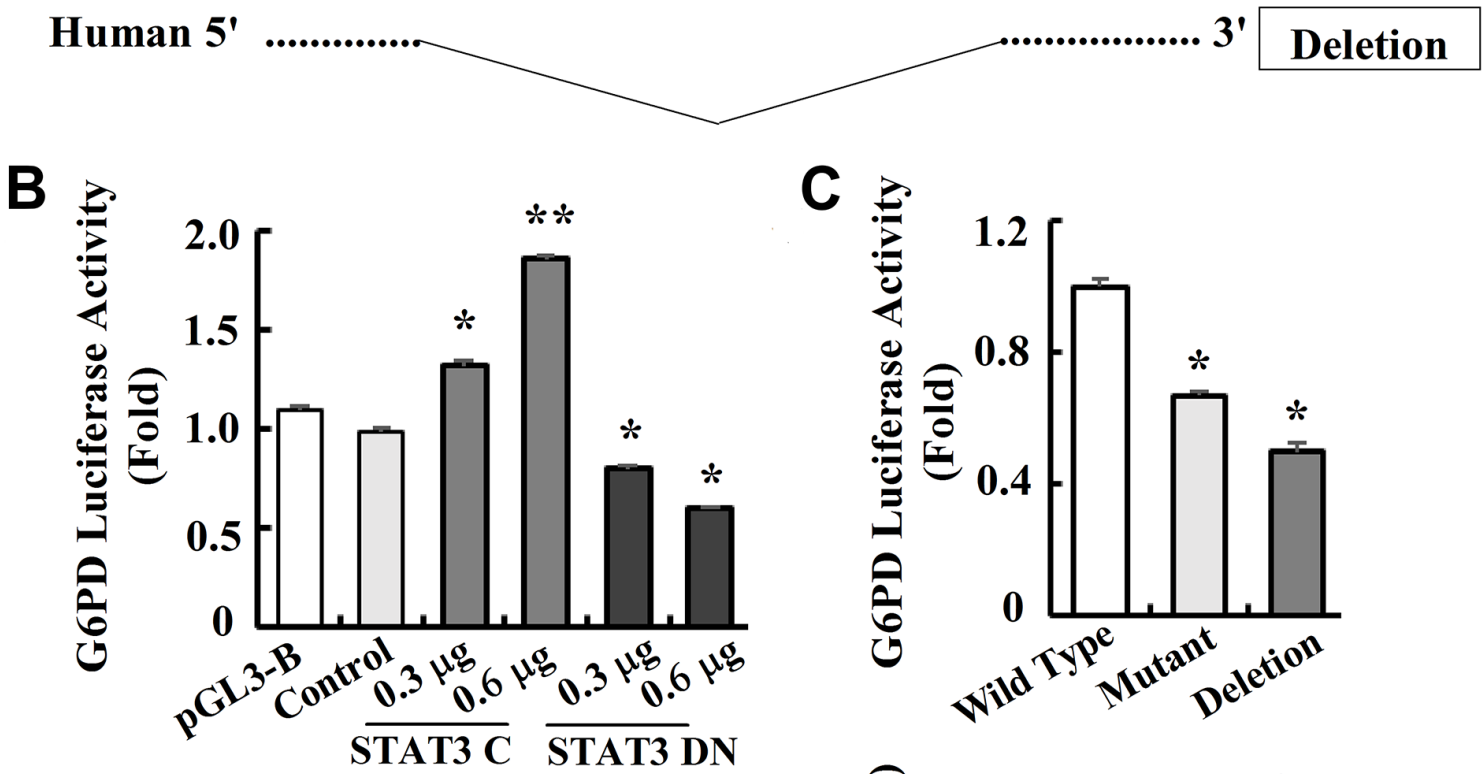

D
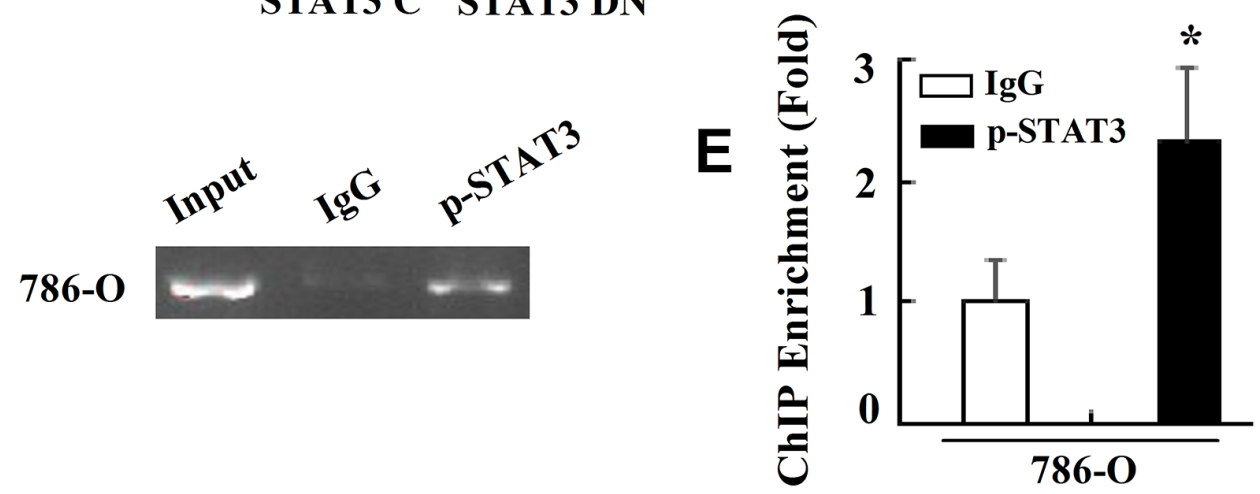

Figure 6: p-STAT3 binds directly to G6PD promoter. (A) MatInspector database analysis of the consensus binding site for p-STAT3 on the G6PD promoter. Sequences containing mutant or deleted base pairs were used to establish the G6PD-luc mutant or deletion luciferase reporter constructs. (B-C) Luciferase reporter assays of p-STAT3 transcriptional activity on the wide type (B) or mutant (C) luciferase reporter constructs were performed. ${ }^{*} p<0.05,{ }^{* *} p<0.01$ vs. Control or Wild type (one-way ANOVA). (D-E) ChIP assay was performed in 786-O cells by RCR (D) or real-time PCR (E) using anti-p-STAT3 antibody or normal IgG as a control. Data represent three independent experiments, each performed in triplicate. Bars represent the means $\pm \mathrm{SD} .{ }^{*} p<0.05 \mathrm{vs}$. IgG (unpaired Student $t$-test). 
persistent activation of $\mathrm{p}$-STAT3 could act as a positive feedback regulator and lead to the aberrant transcription of G6PD in RCC.

\section{DISCUSSION}

In the present study, we aimed to clarify the function of G6PD in promoting RCC proliferation and unravel the potential mechanisms underlying this regulation. Several studies have demonstrated that served as the main producer of ROS in RCC, NOX4 suppression could abrogate RCC cells proliferation, invasion, colony formation, and tumor growth [19, 20]. However, whether the oncogenic function of NOX4 is implicated with ROS generation remains largely undefined. Moreover, why NOX4 activities become up-regulated and the remaining specific mechanisms underlying the manipulation of ROS production in RCC still need to be elucidated. ROS have been implicated in cancer development through regulation of the redox state of target cells and exert diverse effects on cellular function, by promoting either cell proliferation and tumor progression, or cell death and tumor regression $[30,31]$, suggesting that ROS increment is a double-edged sword in tumor cells. Typically, cancer cells are under higher intrinsic levels of oxidative stress than normal cells. This phenomenon can be explained, at least in part, by the hyperactive metabolism reprograming taking place in malignant cells that is required for their rapid growth [32]. However, the levels and functions of ROS, as well as its regulatory factors in RCC development and progression, are largely unknown. Our present report unravel that G6PD plays a critical role in the regulation of RCC redox homeostasis and the elevated levels of NADPH might be an indispensable mediator of NOX4-regulated ROS accumulation. Inducting the exogenous G6PD overexpression up-regulates the production of NADPH, as well as the enzymatic activity of NOX4, and thus leads to the increment of G6PD-NADPH-NOX4-dependent ROS generation in the G6PD promoted RCC carcinogenesis. However, several problems, such as the gene expression alternations of NOX4 or other relevant regulators, remain to be clarified in the future researches.

The function of NOX-derived ROS in the kidney involves not only the alteration of cell fate, but also regulation of gene expression [15]. Pretto F et al found that RCC patients, showing over-activation of STAT3, frequently develop the cachectic syndrome, and that the STAT3 inhibitors are well worth evaluating as a therapeutic option for RCC patients [33]. Reducing p-STAT3 expression can not only significantly inhibit tumor cells proliferation [34, 35], but also migration and invasion in RCC [36]. The importance of ROS-STAT3 in cancer development and therapy has been well reported [37, 38]. Most studies suggested that ROS facilitated abnormal activation of the STAT3 signaling results from increased levels of STAT3 phosphorylation, rather than total STAT3 expression [37, 38]. Meanwhile, some other reports pointed that ROS affected total STAT3 expression via regulating $\mathrm{Sp}$ family transcription factors (TFs), demonstrating that STAT3 is a Sp-regulated target gene [39]. However, as a double-edged sword in tumor proliferation, malignant transformation, apoptosis suppression and immune evasion, ROS from different sources may have different or even completely opposite functions [1]. Here we demonstrate that STAT3, and its active form p-STAT3, are significantly promoted by G6PD-triggered increased ROS production. As a direct transcriptional regulator, STAT3 is constitutively activated and serves as an independent prognostic indicator in RCC $[26,40,41]$. Aberrant p-STAT3 directly binds to the promoter and regulates the expression of a series of cellcycle genes including CyclinD1 that mediates cell survival, proliferation and chemotherapeutic sensitivity [42]. The high frequency of CyclinD1 overexpression observed in RCC patients suggesting that CyclinD1 might contribute to the tumorigenesis and aberrations in the $\mathrm{G}_{1} / \mathrm{S}$ transition of the cell cycle $[43,44]$. Li S et al reported that p-STAT3 inhibition reduces the expression of STAT3-regulated cell survival, proliferation, and angiogenic factors including CyclinD1 [25]. Our data suggest that the CyclinD1 gene expression is positively correlated with the levels of p-STAT3, ROS accumulation and G6PD expression. Moreover, G6PD could regulate CyclinD1 but had a minimal effect on $\mathrm{CDK} 2$ expression in regulating cell cycle distribution of RCC cells (data not shown), implying that CyclinD1 must be a more potential downstream target of G6PD. Although further investigations are required to elucidate the mechanism involved in this regulation, our results definitely support the oncogenic role of G6PD in promoting RCC proliferation.

In this study, the biological functions and underlying molecular mechanisms of G6PD overexpression in RCC tumorigenesis have partially been clarified. However, the question why G6PD is highly expressed and exhibits aberrant activities in a number of human cancers is far from being answered. Previous studies have revealed that G6PD over-activation in human tumors may be attributed to the tumor suppressor p53, the most frequently mutated gene in human tumors, which binds to G6PD, inhibits formation of the active G6PD dimer, and suppresses NADPH production, as well as glucose consumption and biosynthesis [45]. In RCC cells, we find that both the expression level and the activity of G6PD enzyme are up-regulated. Nevertheless, given the fact that only $4 \%$ of ccRCCs present with p53 mutations, enhanced G6PD activities to direct glucose toward biosynthesis and increased tumor cells growth may not be due to p53 inactivation in RCC [46]. Liu B et al reported that G6PD is highly expressed in chronic hepatitis B virus (HBV)-associated liver cancers and upregulated by $\mathrm{HBx}-$ mediated activation of $\mathrm{Nrf} 2$, which may be of importance in the reprogramming of glucose 
A

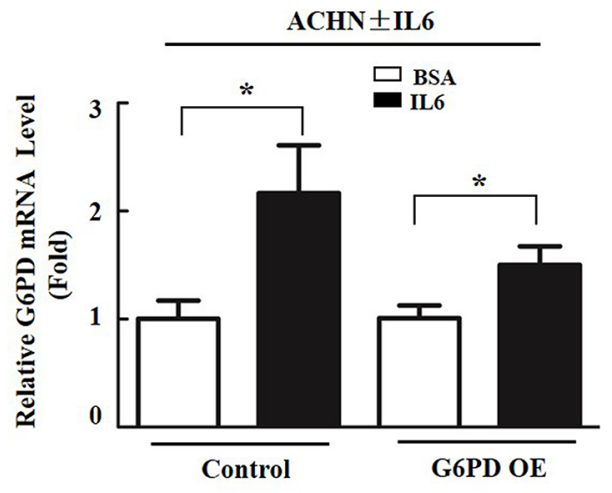

C

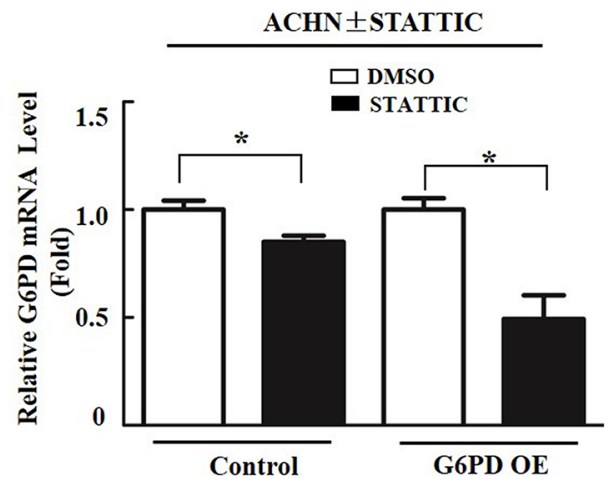

$\mathbf{E}$

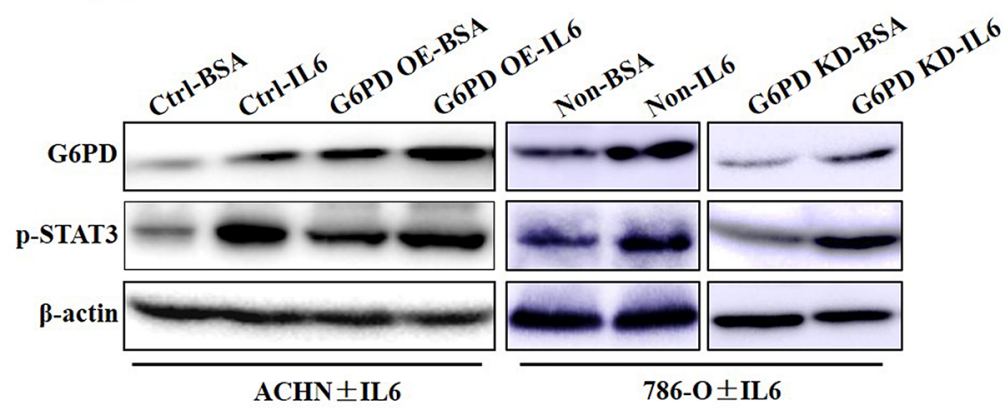

B

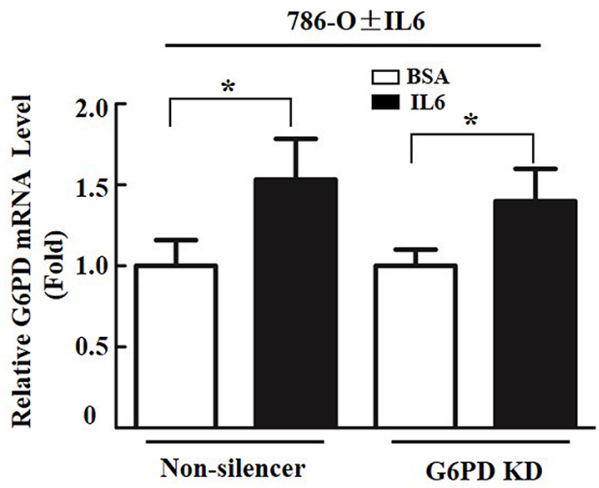

D

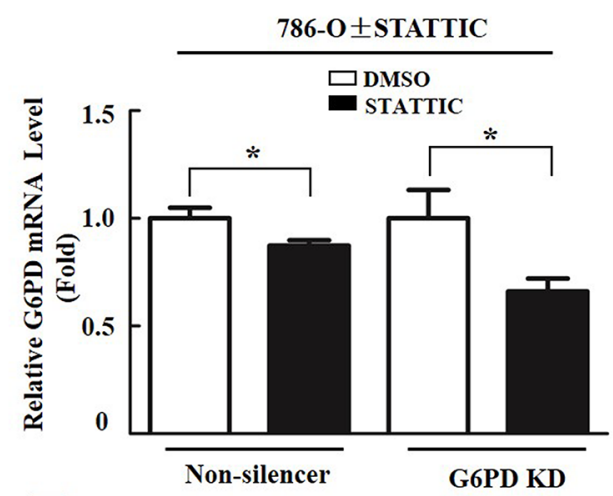

$\mathbf{F}$

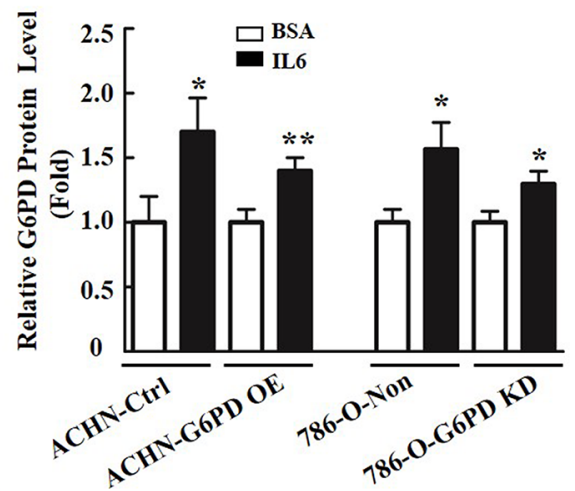

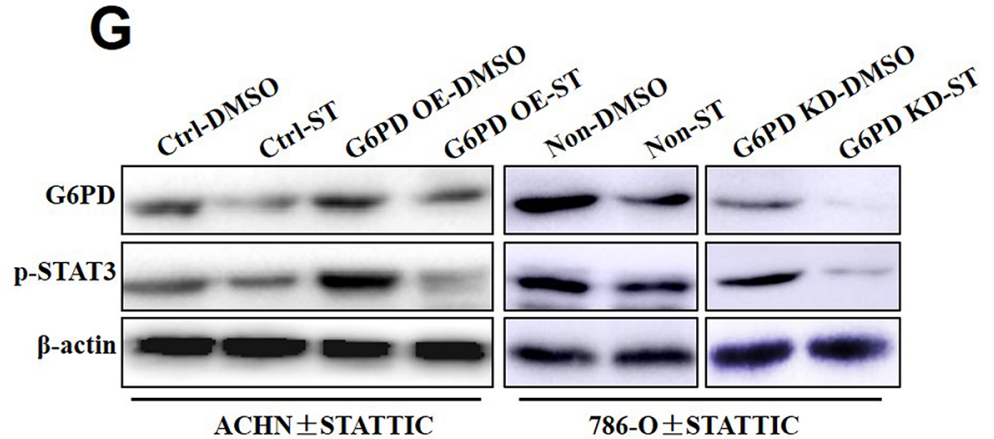

$\mathrm{H}$

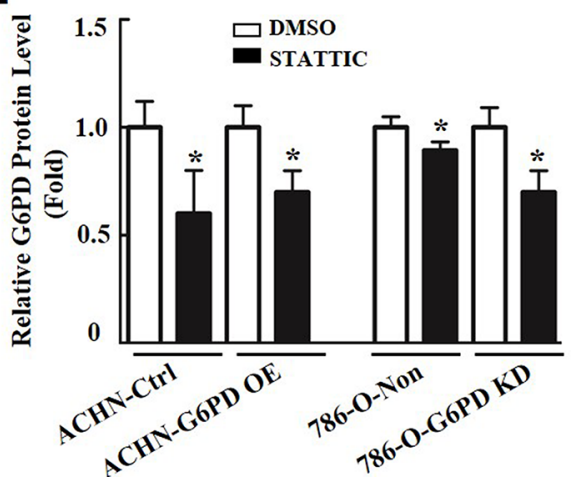

Figure 7: p-STAT3 contributes to G6PD overexpression in RCC cells. Real-time RT-PCR (A-D), Western blot (E, G) and grayscale scanning $(\mathbf{F}, \mathbf{H})$ show the expression changes of G6PD in ACHN and 786-O cells after treated with p-STAT3 activator (IL6, $4 \mathrm{ng} /$ $\mathrm{ml}$ ) or inhibitor (STATTIC, $6 \mu \mathrm{M}$ ) for $24 \mathrm{~h}$. BSA or DMSO treated samples were regarded as "1 fold". Each bar represents mean \pm SD from three independent experiments, each performed in triplicate. ${ }^{*} p<0.05,{ }^{* *} p<0.01$ vs. BSA or DMSO (unpaired Student $t$-test). 
metabolism and development of hepatocarcinoma [47]. However, in RCC, the reason for G6PD up-regulation has not yet been reported. In this study, we attempted to explain the regulatory mechanism underlying G6PD overexpression. The results show that p-STAT3 could recruit to the transcriptional region of the G6PD promoter and activate its expression, demonstrating p-STAT3 has a positive feedback regulation in G6PD overexpression and sheds new light on the mechanism underlying G6PD dysregulation and clinical RCC carcinogenesis.

Both migration and invasion are important aspects in metastasis, with a high likelihood of poor prognosis. In this report, we find that G6PD expression in metastatic RCC patients is significantly higher than that of RCC specimens without lymph node or distant metastasis, indicating that G6PD might play an important role in mediating the progression of RCC to metastasis. Although the mechanism of G6PD in RCC is not fully clarified, we believe that in addition to the proliferation-promoting effect, G6PD may have other functions, especially the potential to facilitate migration and invasion of RCC. Therefore, more investigations are necessary to be carried out for testifying these hypothesis.

In conclusion, our findings demonstrate that G6PD is highly expressed in RCC. Aberrant G6PD could stimulate cell proliferation and tumor growth by activating the G6PD-ROS-p-STAT3-CyclinD1 signaling pathway. Moreover, $\mathrm{p}$-STAT3 forms a positive feedback regulatory circuitry and contributes to G6PD dysregulation in RCC. Taken together, our research supports the oncogenic role of G6PD in human tumorigenesis, unveils new mechanisms underlying RCC carcinogenesis, and points to strategies of designing innovative therapeutic agents to improve RCC treatment.

\section{MATERIALS AND METHODS}

\section{Transcriptomics data set analysis}

To identify the expression profile of G6PD in human RCC, data mining was performed using the Gene Expression Omnibus (GEO, National Center Biotechnology information, Bethesda, MD, USA). One dataset, GSE53757 (http://www.ncbi.nlm.nih.gov/geo/ query/acc.cgi?acc $=$ GSE53757) containing 72 ccRCC (clear cell renal cell carcinoma, which accounts for 80 90 $\%$ of all RCC cases) [7] and the corresponding control (normal or non-tumor) tissues was analyzed.

\section{Immunohistochemistry}

Human RCC and renal tissue specimens were obtained from the department of pathology at the First and the Second Affiliated Hospital of Kunming Medical University, with the informed consent and approval from the Research Ethics Committee of Kunming
Medical University. All specimens were subjected to immunohistochemistry analysis using the 2-step plus ${ }^{\circledR}$ poly-HRP anti-mouse/rabbit IgG detection system (PV9000, ZSGB-BIO, Beijing, China) with anti-phosphoStat3 (Ser 727) antibody (ab30647, Abcam, Cambridge, U.K.) or anti-G6PD antibody (ab133525, Abcam). The experimental procedure and immunohistologic analysis were performed as described before [4, 48].

\section{Cell culture and stable cell construction}

The RCC cell lines ACHN (ATCC CRL-1611 ${ }^{\mathrm{TM}}$ ), 786-O (ATCC CRL-1932 ${ }^{\mathrm{TM}}$ ), Caki-1 (ATCC CRL-1611 ${ }^{\mathrm{TM}}$ ) and the normal renal tubular epithelial cell line HK-2 (ATCC CRL-2190 ${ }^{\mathrm{TM}}$ ) were purchased from Kunming Institute of Zoology (Chinese Academy of Sciences, China) and routinely cultured in MEM (\#10370-021, Gibco $^{\text {TM }}$ Life Technologies, Grand Island, NY), RPMI1640 (\#11875-085, Gibco), McCOY's 5A media (M9309, Sigma-Aldrich, Louis, MO, USA) and K-SFM medium (\#17005-042, Gibco) containing 10\% FBS, respectively.

To construct stable G6PD-overexpressing cell lines, $2 \times 10^{5} \mathrm{ACHN}$ or $786-\mathrm{O}$ cells were plated in a $60-\mathrm{mm}$ culture dish. At about $50 \%$ confluence, the cells were transfected with $2 \mu \mathrm{g}$ pBABE-puro-G6PD (G6PD OE) or pBABE-puro (Control) plasmid as the control using Lipofectamine 2000 (\#11668019, Invitrogen, Carlsbad, CA, USA). After $48 \mathrm{~h}$ transfection, puromycin resistance screening $(0.5 \mu \mathrm{g} / \mathrm{ml})$ was performed. Single colonies were picked up at 21 days after transfection. To establish stable G6PD knockdown cell lines, the 786-O cells were transfected with pSR-GFP/Neo-G6PD shRNA (G6PD KD) or pSR-GFP/Neo-Non-silencer (Non-silencer) plasmid as the control and then selected using G418 resistance screening $(1000 \mu \mathrm{g} / \mathrm{ml})$ for 21 days. Single colonies were picked up and verified.

\section{Cell treatment, cell proliferation and cell cycle assays}

STATTIC and $\mathrm{H}_{2} \mathrm{O}_{2}$ (sc-202818 and sc-203336) were purchased from Santa Cruz Biotechnology (SantaCruz, CA, USA). N-acetyl-cysteine (NAC, A7250) used as the ROS scavenger, was purchased from Sigma (Louis, MO, USA). STATTIC and NAC were dissolved in $100 \%$ dimethyl sulfoxide to prepare a $40 \mathrm{mM}$ and $600 \mathrm{mM}$ stock, respectively, and stored at $-20^{\circ} \mathrm{C}$. Recombinant human interleukin (IL)-6 purchased from R\&D Systems (206IL, Minneapolis, MN, USA) was reconstituted in sterile PBS containing $0.1 \%$ bovine serum albumin to prepare a $10 \mu \mathrm{g} / \mathrm{ml}$ stock and stored at $-20^{\circ} \mathrm{C}$. The stock solution was added to the culture medium to achieve the indicated final concentrations. Cell proliferation was measured using the Cell Counting Kit-8 (CCK-8) (Dojindo Laboratories, Kumamoto, Japan), according to the manufacturer's protocol. The plate clone formation 
assay, cell cycle assessment and data analysis were carried out based on our previous report [48-50].

\section{Animal experiments}

All animal experiments were approved by the Institutional Animal Care and Use Committee of Kunming Medical University. $1 \times 10^{7} \mathrm{RCC}$ cells were resuspended in $200 \mu \mathrm{lBS}$ and injected subcutaneously into the right oxter flank of each six-week-old female BALB/c nude mice (purchase from Beijing HFK Bioscience Co., Ltd, Beijing, China), four mice per group. Tumor sizes were measured at indicated days, and tumor volumes were calculated according to the equation: volume $=$ length $\times$ width $^{2} \times(1 / 2)$. Following, the mice were sacrificed by euthanasia and the tumors were harvested.

\section{Real-time RT-PCR}

Total RNA was isolated using the Trizol Reagent (Invitrogen ${ }^{\mathrm{TM}}$, Shanghai, China) based on the manufacturer's instructions. Real-time RT-PCR amplifications were performed as described before [51] using different primers: G6PD: F: 5'-TGAGCCAGAT AGGCTGGAA-3'， R: 5'-TAACGCAGGCGATGTTG TC-3'; CyclinD1: F: 5'-GCGTACCCTGACACCCCTC TC-3', R: 5'-CTCCTCTTCGCCTGATCC-3'; GAPDH: F: 5'-CGACCACTTTGTCAAGCTCA-3'，R: 5'-AGG GGTCTACATGGCAACTG-3'.

\section{Western blot}

Cell lysates were prepared using the RIPA lysis buffer (R0010, Solarbio, Beijing, China) containing protease inhibitors (B14001, biotool, Shanghai, China). Western blot analysis was carried out as described before [52]. The antibody used in the experiment included the anti-G6PD antibody (ab133525, Abcam, Cambridge, U.K.); anti-phospho-Stat3 antibody (Ser 727) (ab30647, Abcam), and anti-CyclinD1 antibody (ab16663, Abcam). Additionally, anti-STAT3 antibody (\#4904), anti- $\beta$-actin (\#4967) antibody, and anti-GAPDH antibody (\#2118) were purchased from Cell Signaling Technology (Beverly, MA, USA).

\section{G6PD and NOX oxidases activities}

G6PD and NOX4 activities were analyzed using the G6PD or NOX4 assay kit (GMS70013.1 and GMS50096.1, GENMED, Shanghai, China) according to the manufacturer instructions. For the G6PD activity assay, $4 \times 10^{6}$ cells were firstly pelleted using Reagent A. The cells were then lysed with $500 \mu$ l Reagent B in a microfuge tube and kept on ice for $30 \mathrm{~min}$. Following, they were centrifuged at $13,000 \times \mathrm{g}$ for $5 \mathrm{~min}$, and the supernatant was collected. $195 \mu \mathrm{l}$ Reagent C, $25 \mu \mathrm{l}$ Reagent $\mathrm{D}$, and $25 \mu 1$ Reagent E ( $5 \mu 1$ Reagent F for NOX oxidases activity assay) were successively added into a labeled 96-well plate in duplicate, and the template was incubated in a $30^{\circ} \mathrm{C}$ incubator for $3 \mathrm{~min} .5 \mu \mathrm{l}$ of each sample $(20 \mu \mathrm{g}$ protein) or negative control (Reagent F) was pipetted into each well. For the NOX oxidases activity assay, $25 \mu \mathrm{l}$ of cell sample ( $20 \mu \mathrm{g}$ protein) or negative control (Reagent E) was transferred into each well. The absorbance was measured at OD $340 \mathrm{~nm}$ using the U-1800 ultraviolet spectrophotometer (Hitachi, Japan) at $0 \mathrm{~min}$ and $15 \mathrm{~min}$. The activities of G6PD or NOX4 were then calculated according to the formula: Activity $(\mathrm{U} / \mathrm{mg})=$ $\left(\mathrm{OD}_{\text {sample }}-\mathrm{OD}_{\text {negative control }} \times 0.25 \times\right.$ dilution times $) / 0.005$ $\times 6.25 \times 0.6 \times 5$.

\section{NADPH Levels}

To measure NADPH levels, a colorimetric assay kit (k347-100, Bio Vision, Milpitas, USA) was used as described in the manufacturer instructions. $4 \times 10^{6}$ cells were firstly pelleted for each assay in a microcentrifuge tube at $2000 \mathrm{rpm}$ for $5 \mathrm{~min}$. The cells were then lysed with $800 \mu \mathrm{l}$ of NADP/NADPH Extraction Buffer in a microfuge tube and keep on ice for $10 \mathrm{~min}$, followed by spinning down at 12,000 rpm for $10 \mathrm{~min}$, and supernatant collection. Then, the extracted NADP/NADPH solution was transferred into a new labeled tube. To detect NADPH only, $200 \mu \mathrm{l}$ were aliquoted into EP tubes. The samples were then heated to $60^{\circ} \mathrm{C}$ for $30 \mathrm{~min}$ in a water bath. Under the conditions, all NADP will decompose while NADPH will remain intact. The samples were then cooled on ice and quick-spun if precipitation occurred. $50 \mu \mathrm{l}$ of NADPH samples were then transferred into a labeled 96well plate in duplicates. $10 \mu \mathrm{l}$ NADPH developer was added into each well and the reaction developed for $1 \mathrm{~h}$ $\sim 4 \mathrm{~h}$. The plate was read at OD $450 \mathrm{~nm}$ in an U-1800 ultraviolet spectrophotometer (Hitachi, Japan). The OD $450 \mathrm{~nm}$ reading for each sample was compared to the standard curve and the amount of NADPH was expressed in $\mu \mathrm{mol} / \mu \mathrm{g}$ protein.

\section{ROS level accumulation assays}

Reactive oxygen species (ROS) in RCC cells were detected using the ROS Fluorescent Probe-DHE (R001, Vigorous Biotechnology, Beijing, China) and according to the supplier instructions [24]. Before the absorbance was assessed by flow cytometry, the images were firstly acquired with a BX51 fluorescence microscope (Olympus, Japan). Following, the fluorescence intensities were detected by flow cytometry at $530 \mathrm{~nm}$ excitation and $620 \mathrm{~nm}$ emission wavelengths.

\section{Luciferase reporter assays}

The plasmid transfection and luciferase activity detection were performed as described before [51]. G6PDluc, G6PD-luc Mutant and Deletion were commercially 
constructed by Shanghai Generay Biotech Co., Ltd (Shanghai, China). STAT3 C and STAT3 DN were purchased from Addgene (\#24983 and \#24984, Addgene, MA, USA).

\section{Chromatin immunoprecipitation (ChIP) assays}

The ChIP assays were performed in 786-O cells according to the method described by Shang $\mathrm{Y}$ et al [53] using anti-phospho-Stat3 (Ser 727) antibody (ab30647, Abcam, Cambridge, U.K.) and primer (covering -1729 to -1493 of G6PD promoter region): F: 5'-TTGGCCAGTGCTCCAGAA-3', R: 5'-ACCGCGAAACTGGGACTTTCT-3'.

\section{Statistical analysis}

Bioinformatics analysis of the differences in G6PD expression between the ccRCC and control tissues were evaluated using the Wilcoxon rank-sum test in the $\mathrm{R}$ (http://www.r-project.org/) software environment. Bonferroni correction of the R function " $\mathrm{p}$. adjust" was used to adjust the $p$ values. Experimental analyses were carried out using SPSS version 20.0. For immunohistologic analysis, the differences of G6PD expression between RCC and paired adjacent normal tissues was assessed using the $\chi^{2}$ test; the differences of G6PD in adjacent normal tissues or RCC specimens from patients, with or without metastasis, were calculated using the Kruskal-Wallis one-way analysis of variances. The correlation between G6PD and p-STAT3 expression was assessed using Spearman correlation analysis. During animal experiments, the significance of the difference in tumor volumes between the groups was determined using two-way ANOVA. For the other analyses, the differences between groups were determined using unpaired Student $t$-test $(n=2)$ or one-way ANOVA $(n \geq 3)$. The data are expressed as means \pm standard deviation (S.D.) of three independent experiments, each performed in triplicate. $p<0.05$ was considered to be statistically significant.

\section{Abbreviations}

G6PD: glucose-6-phosphate dehydrogenase; PPP: pentose phosphate pathway; RCC: renal cell carcinoma; ccRCC: clear cell renal cell carcinoma; ROS: reactive oxygen species; NADPH: nicotinamide adenine dinucleotide phosphate; NOX: NADPH oxidase; GEO: Gene Expression Omnibus; TCGA: The Cancer Genome Atlas; pRCC: papillary renal cell carcinoma; chRCC: chromophobe renal cell carcinoma; CCK-8: Cell Counting Kit-8; STAT3: signal transducer and activator of transcription 3; NAC: N-acetyl-cysteine; ChIP: chromatin immunoprecipitation; IL6: interleukin 6; HBV: hepatitis $B$ virus.

\section{Author contributions}

$\mathrm{YZ}, \mathrm{YK}$ and $\mathrm{QZ}$ conceived and designed the experiments; QZ, QH, HB and YW performed the experiments and analyzed the data; XY, ZY, LY and LJ contributed reagents/materials/analysis tools; QZ, YZ and $\mathrm{XS}$ wrote the paper. All authors read and approved the final manuscript.

\section{ACKNOWLEDGMENTS}

We thank Prof. Ceshi Chen, Kunming Institute of Zoology, Chinese Academy of Sciences, China, for his useful discussion during the reports preparation.

\section{CONFLICTS OF INTEREST}

The authors declared that they have no competing interest.

\section{FUNDING}

This work was supported by the National Science Foundation of China (No. 81160426, 81460421, 81560037, 31660246, 81660135, 81760455), Yunnan ProvinceKunming Medical University joint Foundation for Applied Basic Research (No. 2013FB102, 2017FE468(-003), 2017FE468(-132), 2017FE468(-141), 2018FE468(-001)), Yunnan Provincial Education Department Fund Project (No. 2015Y178, 2015J057, 2016YJS048), and Doctoral Research Foundation of Kunming Medical University (JD201502).

\section{REFERENCES}

1. Zhang C, Zhang Z, Zhu Y, Qin S. Glucose-6-phosphate dehydrogenase: a biomarker and potential therapeutic target for cancer. Anticancer Agents Med Chem. 2014; 14: 280-9.

2. Ju HQ, Lu YX, Wu QN, Liu J, Zeng ZL, Mo HY, Chen Y, Tian T, Wang Y, Kang TB, Xie D, Zeng MS, Huang P, et al. Disrupting G6PD-mediated Redox homeostasis enhances chemosensitivity in colorectal cancer. Oncogene. 2017; 36: 6282-92. https://doi.org/10.1038/onc.2017.227.

3. Hanahan D, Weinberg RA. Hallmarks of cancer: the next generation. Cell. 2011; 144: 646-74. https://doi. org/10.1016/j.cell.2011.02.013.

4. Zhang Q, Yi X, Yang Z, Han Q, Di X, Chen F, Wang Y, Yi Z, Kuang Y, Zhu Y. Overexpression of G6PD represents a potential prognostic factor in clear cell renal cell carcinoma. J Cancer. 2017; 8: 665-73. https://doi.org/10.7150/ jca.16858.

5. Chinello C, Cazzaniga M, De Sio G, Smith AJ, Grasso A, Rocco B, Signorini S, Grasso M, Bosari S, Zoppis I, Mauri G, Magni F. Tumor size, stage and grade alterations 
of urinary peptidome in RCC. J Transl Med. 2015; 13: 332. https://doi.org/10.1186/s12967-015-0693-8.

6. Hosoya N, Sakumoto M, Nakamura Y, Narisawa T, Bilim V, Motoyama T, Tomita Y, Kondo T. Proteomics identified nuclear N-myc downstream-regulated gene 1 as a prognostic tissue biomarker candidate in renal cell carcinoma. Biochim Biophys Acta. 2013; 1834: 2630-9. https://doi.org/10.1016/j.bbapap.2013.08.009.

7. Busch J, Ralla B, Jung M, Wotschofsky Z, Trujillo-Arribas E, Schwabe P, Kilic E, Fendler A, Jung K. Piwi-interacting RNAs as novel prognostic markers in clear cell renal cell carcinomas. J Exp Clin Cancer Res. 2015; 34: 61. https:// doi.org/10.1186/s13046-015-0180-3.

8. Linehan WM, Srinivasan R, Schmidt LS. The genetic basis of kidney cancer: a metabolic disease. Nat Rev Urol. 2010; 7: 277-85. https://doi.org/10.1038/nrurol.2010.47.

9. Vavallo A, Simone S, Lucarelli G, Rutigliano M, Galleggiante V, Grandaliano G, Gesualdo L, Campagna M, Cariello M, Ranieri E, Pertosa G, Lastilla G, Selvaggi FP, et al. Pre-existing type 2 diabetes mellitus is an independent risk factor for mortality and progression in patients with renal cell carcinoma. Medicine (Baltimore). 2014; 93: e183. https://doi.org/10.1097/MD.037283R1037283R10183.

10. Cancer Genome Atlas Research Network. Comprehensive molecular characterization of clear cell renal cell carcinoma. Nature. 2013; 499: 43-9. https://doi.org/10.1038/nature12222.

11. Von Roemeling CA, Marlow LA, Radisky DC, Rohl A, Larsen HE, Wei J, Sasinowska H, Zhu H, Drake R, Sasinowski M, Tun HW, Copland JA. Functional genomics identifies novel genes essential for clear cell renal cell carcinoma tumor cell proliferation and migration. Oncotarget. 2014; 5: 5320-34. https://doi.org/10.18632/ oncotarget.2097.

12. White NM, Masui O, Desouza LV, Krakovska O, Metias S, Romaschin AD, Honey RJ, Stewart R, Pace K, Lee J, Jewett MA, Bjarnason GA, Siu KW, et al. Quantitative proteomic analysis reveals potential diagnostic markers and pathways involved in pathogenesis of renal cell carcinoma. Oncotarget. 2014; 5: 506-18. https://doi.org/10.18632/ oncotarget.1529.

13. Lin HR, Wu YH, Yen WC, Yang CM, Chiu DT. Diminished COX-2/PGE2-mediated antiviral response due to impaired NOX/MAPK signaling in G6PD-knockdown lung epithelial cells. PLoS One. 2016; 11: e0153462. https://doi. org/10.1371/journal.pone.0153462.

14. Kathagen-Buhmann A, Schulte A, Weller J, Holz M, Herold-Mende C, Glass R, Lamszus K. Glycolysis and the pentose phosphate pathway are differentially associated with the dichotomous regulation of glioblastoma cell migration versus proliferation. Neuro Oncol. 2016; 18: 1219-29. https://doi.org/10.1093/neuonc/now024.

15. Bedard K, Krause KH. The NOX family of ROS-generating NADPH oxidases: physiology and pathophysiology. Physiol Rev. 2007; 87: 245-313. https://doi.org/10.1152/ physrev.00044.2005.
16. Brandt M, Garlapati V, Oelze M, Sotiriou E, Knorr M, Kroller-Schon S, Kossmann S, Schonfelder T, Morawietz H, Schulz E, Schultheiss HP, Daiber A, Munzel T, et al. NOX2 amplifies acetaldehyde-mediated cardiomyocyte mitochondrial dysfunction in alcoholic cardiomyopathy. Sci Rep. 2016; 6: 32554. https://doi.org/10.1038/srep32554.

17. Katsuyama M, Matsuno $\mathrm{K}$, Yabe-Nishimura $\mathrm{C}$. Physiological roles of NOX/NADPH oxidase, the superoxide-generating enzyme. J Clin Biochem Nutr. 2012; 50: 9-22. https://doi.org/10.3164/jcbn.11-06SR.

18. Fitzgerald JP, Nayak B, Shanmugasundaram K, Friedrichs W, Sudarshan S, Eid AA, DeNapoli T, Parekh DJ, Gorin Y, Block K. Nox4 mediates renal cell carcinoma cell invasion through hypoxia-induced interleukin 6- and 8- production. PLoS One. 2012; 7: e30712. https://doi.org/10.1371/journal. pone. 0030712 .

19. Maranchie JK, Zhan Y. Nox4 is critical for hypoxiainducible factor 2-alpha transcriptional activity in von Hippel-Lindau-deficient renal cell carcinoma. Cancer Res. 2005; 65: 9190-3. https://doi.org/10.1158/0008-5472. CAN-05-2105.

20. Gregg JL, Turner RM 2nd, Chang G, Joshi D, Zhan Y, Chen L, Maranchie JK. NADPH oxidase NOX4 supports renal tumorigenesis by promoting the expression and nuclear accumulation of HIF2alpha. Cancer Res. 2014; 74: 350111. https://doi.org/10.1158/0008-5472.CAN-13-2979.

21. Brandes RP, Weissmann N, Schroder K. Nox family NADPH oxidases: molecular mechanisms of activation. Free Radic Biol Med. 2014; 76: 208-26. https://doi. org/10.1016/j.freeradbiomed.2014.07.046.

22. Wang YP, Zhou LS, Zhao YZ, Wang SW, Chen LL, Liu LX, Ling ZQ, Hu FJ, Sun YP, Zhang JY, Yang C, Yang Y, Xiong $\mathrm{Y}$, et al. Regulation of G6PD acetylation by SIRT2 and KAT9 modulates NADPH homeostasis and cell survival during oxidative stress. EMBO J. 2014; 33: 1304-20. https://doi.org/10.1002/embj.201387224.

23. Sinha R, Winer AG, Chevinsky M, Jakubowski C, Chen YB, Dong Y, Tickoo SK, Reuter VE, Russo P, Coleman JA, Sander C, Hsieh JJ, Hakimi AA. Analysis of renal cancer cell lines from two major resources enables genomicsguided cell line selection. Nat Commun. 2017; 8: 15165. https://doi.org/10.1038/ncomms15165.

24. Cai T, Kuang Y, Zhang C, Zhang Z, Chen L, Li B, Li Y, Wang Y, Yang H, Han Q, Zhu Y. Glucose-6-phosphate dehydrogenase and NADPH oxidase 4 control STAT3 activity in melanoma cells through a pathway involving reactive oxygen species, c-SRC and SHP2. Am J Cancer Res. 2015; 5: 1610-20.

25. Li S, Priceman SJ, Xin H, Zhang W, Deng J, Liu Y, Huang J, Zhu W, Chen M, Hu W, Deng X, Zhang J, Yu H, et al. Icaritin inhibits JAK/STAT3 signaling and growth of renal cell carcinoma. PLoS One. 2013; 8: e81657. https://doi. org/10.1371/journal.pone.0081657.

26. Cuadros T, Trilla E, Sarro E, Vila MR, Vilardell J, de Torres I, Salcedo M, Lopez-Hellin J, Sanchez A, Ramon 
y Cajal S, Itarte E, Morote J, Meseguer A. HAVCR/KIM-1 activates the IL-6/STAT-3 pathway in clear cell renal cell carcinoma and determines tumor progression and patient outcome. Cancer Res. 2014; 74: 1416-28. https://doi. org/10.1158/0008-5472.can-13-1671.

27. Xu X, Sun YL, Hoey T. Cooperative DNA binding and sequence-selective recognition conferred by the STAT amino-terminal domain. Science. 1996; 273: 794-7.

28. Chen J, Fu R, Cui Y, Li YS, Pan JR, Liu JL, Luo HS, Yin JD, Li DF, Cui S. LIM-homeodomain transcription factor Isl-1 mediates the effect of leptin on insulin secretion in mice. J Biol Chem. 2013; 288: 12395-405. https://doi. org/10.1074/jbc.M113.450536.

29. Bromberg JF, Wrzeszczynska MH, Devgan G, Zhao Y, Pestell RG, Albanese C, Darnell JE Jr. Stat3 as an oncogene. Cell. 1999; 98: 295-303.

30. Waris G, Ahsan H. Reactive oxygen species: role in the development of cancer and various chronic conditions. J Carcinog. 2006; 5: 14. https://doi. org/10.1186/1477-3163-5-14.

31. Wang J, Yi J. Cancer cell killing via ROS: to increase or decrease, that is the question. Cancer Biol Ther. 2008; 7: 1875-84.

32. Rhee SG. Cell signaling. H2O2, a necessary evil for cell signaling. Science. 2006; 312: 1882-3. https://doi. org/10.1126/science. 1130481 .

33. Pretto F, Ghilardi C, Moschetta M, Bassi A, Rovida A, Scarlato V, Talamini L, Fiordaliso F, Bisighini C, Damia G, Bani MR, Piccirillo R, Giavazzi R. Sunitinib prevents cachexia and prolongs survival of mice bearing renal cancer by restraining STAT3 and MuRF-1 activation in muscle. Oncotarget. 2015; 6: 3043-54. https://doi.org/10.18632/ oncotarget.2812.

34. Horiguchi A, Asano T, Kuroda K, Sato A, Asakuma J, Ito K, Hayakawa M, Sumitomo M, Asano T. STAT3 inhibitor WP1066 as a novel therapeutic agent for renal cell carcinoma. Br J Cancer. 2010; 102: 1592-9. https://doi. org/10.1038/sj.bjc.6605691.

35. Kim C, Baek SH, Um JY, Shim BS, Ahn KS. Resveratrol attenuates constitutive STAT3 and STAT5 activation through induction of PTPepsilon and SHP-2 tyrosine phosphatases and potentiates sorafenib-induced apoptosis in renal cell carcinoma. BMC Nephrol. 2016; 17: 19. https:// doi.org/10.1186/s12882-016-0233-7.

36. Fang Z, Tang Y, Fang J, Zhou Z, Xing Z, Guo Z, Guo X, Wang W, Jiao W, Xu Z, Liu Z. Simvastatin inhibits renal cancer cell growth and metastasis via AKT/mTOR, ERK and JAK2/STAT3 pathway. PLoS One. 2013; 8: e62823. https://doi.org/10.1371/journal.pone.0062823.

37. Fan TF, Wu TF, Bu LL, Ma SR, Li YC, Mao L, Sun ZJ, Zhang WF. Dihydromyricetin promotes autophagy and apoptosis through ROS-STAT3 signaling in head and neck squamous cell carcinoma. Oncotarget. 2016; 7: 59691-703. https://doi.org/10.18632/oncotarget.10836.
38. Cheng SE, Lee IT, Lin CC, Wu WL, Hsiao LD, Yang CM. ATP mediates NADPH oxidase/ROS generation and COX-2/PGE2 expression in A549 cells: role of $\mathrm{P} 2$ receptordependent STAT3 activation. PLoS One. 2013; 8: e54125. https://doi.org/10.1371/journal.pone.0054125.

39. Kasiappan R, Jutooru I, Karki K, Hedrick E, Safe S. Benzyl isothiocyanate (BITC) induces reactive oxygen speciesdependent repression of STAT3 protein by down-regulation of specificity proteins in pancreatic cancer. J Biol Chem. 2016; 291: 27122-33. https://doi.org/10.1074/jbc.M116.746339.

40. Horiguchi A, Oya M, Shimada T, Uchida A, Marumo K, Murai M. Activation of signal transducer and activator of transcription 3 in renal cell carcinoma: a study of incidence and its association with pathological features and clinical outcome. J Urol. 2002; 168: 762-5.

41. Lue HW, Cole B, Rao SA, Podolak J, Van Gaest A, King C, Eide CA, Wilmot B, Xue C, Spellman PT, Heiser LM, Tyner JW, Thomas GV. Src and STAT3 inhibitors synergize to promote tumor inhibition in renal cell carcinoma. Oncotarget. 2015; 6: 44675-87. https://doi.org/10.18632/ oncotarget.5971.

42. Qin A, Yu Q, Gao Y, Tan J, Huang H, Qiao Z, Qian W. Inhibition of STAT3/cyclinD1 pathway promotes chemotherapeutic sensitivity of colorectal caner. Biochem Biophys Res Commun. 2015; 457: 681-7. https://doi. org/10.1016/j.bbrc.2015.01.048.

43. Lima MS, Pereira RA, Costa RS, Tucci S, Dantas M, Muglia VF, Ravinal RC, Barros-Silva GE. The prognostic value of cyclin D1 in renal cell carcinoma. Int Urol Nephrol. 2014; 46: 905-13. https://doi.org/10.1007/ s11255-013-0602-0.

44. Hedberg Y, Ljungberg B, Roos G, Landberg G. Expression of cyclin D1, D3, E, and p27 in human renal cell carcinoma analysed by tissue microarray. Br J Cancer. 2003; 88: 141723. https://doi.org/10.1038/sj.bjc.6600922.

45. Jiang P, Du W, Wang X, Mancuso A, Gao X, Wu M, Yang $\mathrm{X}$. p53 regulates biosynthesis through direct inactivation of glucose-6-phosphate dehydrogenase. Nat Cell Biol. 2011; 13: 310-6. https://doi.org/10.1038/ncb2172.

46. Kang JH, Lee JS, Hong D, Lee SH, Kim N, Lee WK, Sung TW, Gong YD, Kim SY. Renal cell carcinoma escapes death by p53 depletion through transglutaminase 2-chaperoned autophagy. Cell Death Dis. 2016; 7: e2163. https://doi. org/10.1038/cddis.2016.14.

47. Liu B, Fang M, He Z, Cui D, Jia S, Lin X, Xu X, Zhou T, Liu W. Hepatitis B virus stimulates G6PD expression through HBx-mediated Nrf2 activation. Cell Death Dis. 2015; 6: e1980. https://doi.org/10.1038/cddis.2015.322.

48. Zhang Q, Yang Z, Jia Z, Liu C, Guo C, Lu H, Chen P, Ma K, Wang W, Zhou C. ISL-1 is overexpressed in non-Hodgkin lymphoma and promotes lymphoma cell proliferation by forming a p-STAT3/p-c-Jun/ ISL-1 complex. Mol Cancer. 2014; 13: 181. https://doi. org/10.1186/1476-4598-13-181. 
49. Guo T, Wang W, Zhang H, Liu Y, Chen P, Ma K, Zhou C. ISL1 promotes pancreatic islet cell proliferation. PLoS One. 2011; 6: e22387. https://doi.org/10.1371/journal.pone.0022387.

50. Shi Q, Wang W, Jia Z, Chen P, Ma K, Zhou C. ISL1, a novel regulator of CCNB1, CCNB2 and c-MYC genes, promotes gastric cancer cell proliferation and tumor growth. Oncotarget. 2016; 7: 36489-500. https://doi.org/10.18632/ oncotarget.9269.

51. Liu Y, Li Y, Li T, Lu H, Jia Z, Wang W, Chen P, Ma K, Zhou C. POU homeodomain protein OCT1 modulates islet 1 expression during cardiac differentiation of P19CL6 cells. Cell Mol Life Sci. 2011; 68: 1969-82. https://doi. org/10.1007/s00018-010-0544-y.

52. Liu Z, Li T, Liu Y, Jia Z, Li Y, Zhang C, Chen P, Ma K, Affara N, Zhou C. WNT signaling promotes Nkx2.5 expression and early cardiomyogenesis via downregulation of Hdac1. Biochim Biophys Acta. 2009; 1793: 300-11. https://doi.org/10.1016/j.bbamcr.2008.08.013.

53. Shang Y, Hu X, DiRenzo J, Lazar MA, Brown M. Cofactor dynamics and sufficiency in estrogen receptor-regulated transcription. Cell. 2000; 103: 843-52. 